\title{
ANAIS DO I CONGRESSO DE MEDICINA ESPORTIVA DO CENTRO-OESTE MINEIRO CMECOM 2019
}

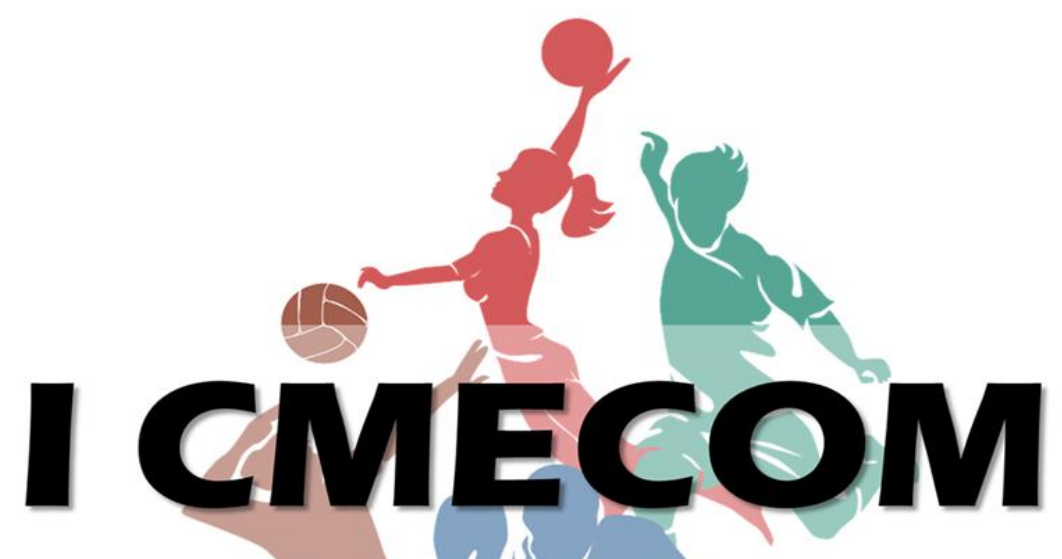

I Congresso de Medicina Esportiva do Centro Oeste Mineiro
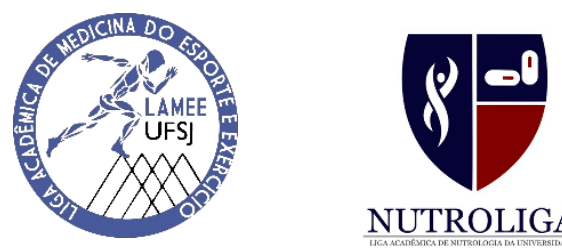

NUTROLIGA

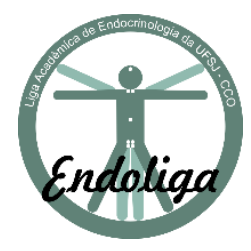

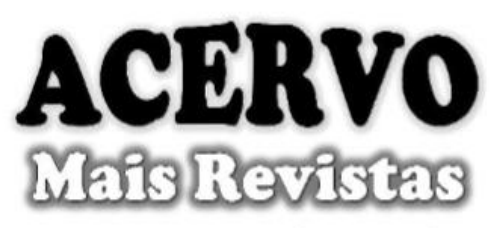

www.acervomais.com.br

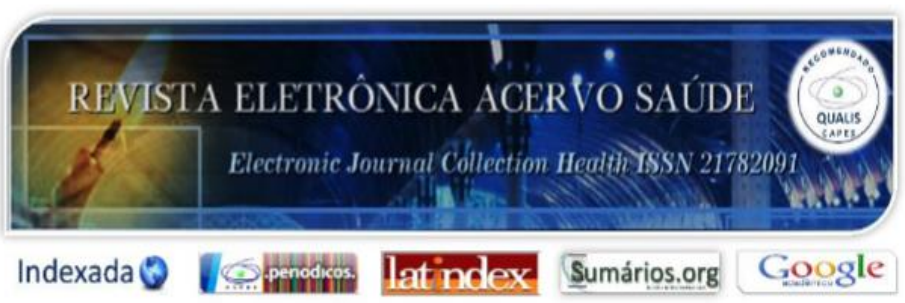

Divinópolis/MG

2019 


\section{COMISSÃO ORGANIZADORA DO I CONGRESSO DE MEDICINA ESPORTIVA DO CENTRO-OESTE MINEIRO}

\section{Coordenação Geral:}

Discentes:

Luciano Fernandes de Oliveira Filho

Rachel Laguardia Rego

Rafaela Candian Filgueiras Silva

Docente:

Vinícius Azevedo Dias

\section{Coordenação Científica:}

Pedro Henrique Ferreira

Maria Luísa Miranda Resende

Fernanda Mota Franco

\section{Comissão Organizadora:}

Brenda Oliveira

Cecília Almeida e Amaral Faria

Daniela Carvalho Siqueira

Frederico Bregunci de Castro

Ingrid Morselli Santos

Juliana Moreira Maia

Laís Cristina de Melo Silva

Olívia Maria Trindade

Paula Fontes Lelis

Priscila Cristian do Amaral

Vanessa Cavazana Takata

William Alves Bueno 


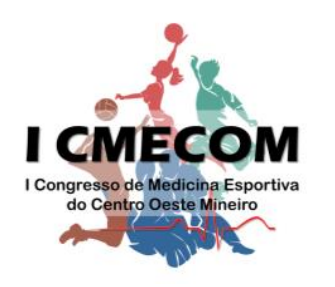

\section{ANAIS DO I CONGRESSO DE MEDICINA ESPORTIVA DO CENTRO-OESTE MINEIRO}

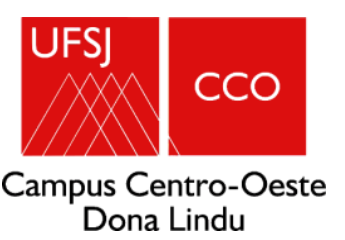

\section{APRESENTAÇÃO DO EVENTO}

I Congresso de Medicina Esportiva do Centro Oeste Mineiro (I CMECOM) é um evento científico, sem fins lucrativos, fruto da parceria de três ligas acadêmicas da Universidade Federal de São João Del-Rei (UFSJ), campus Centro Oeste, a saber: Liga Acadêmica de Endocrinologia - ENDOLIGA, Liga Acadêmica de Medicina do Esporte e Exercício - LAMEE, e Liga Acadêmica de Nutrologia - NUTROLIGA. O evento tem como objetivo difundir e discutir os conhecimentos acerca da Medicina Esportiva, com abordagem multiprofissional de modo a incluir diversos cursos da área da saúde, como Medicina, Enfermagem, Fisioterapia, Educação Física, Farmácia e Nutrição. Assim, a abrangência de público para o evento incluirá todos os acadêmicos das faculdades e/ou universidades de Divinópolis e região que possuem cursos de graduação relacionados ao tema central do evento, bem como os profissionais atuantes nessa área.

Todos os eventos científicos por si sós, são importantes, tratam-se de ambientes em que profissionais e acadêmicos têm contato com as principais novidades em determinado campo de atuação, possibilitando trocas de conhecimento e obtenção de novas experiências. E essa é a proposta do I CMECOM: proporcionar abertura para que profissionais de saúde se mantenham atualizados diante da realidade da Medicina Esportiva, que vive em intensa e constante transformação.

Atenciosamente,
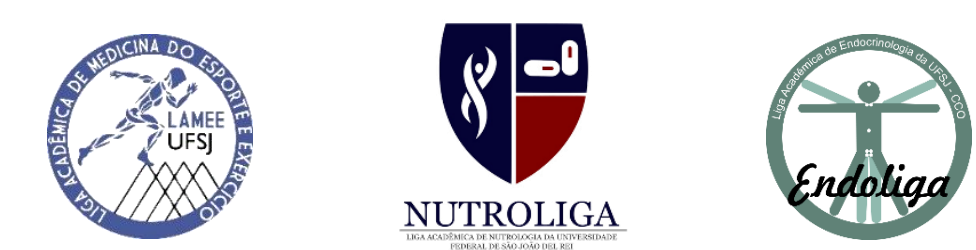

Comissão Organizadora do I Congresso de Medicina Esportiva do Centro-Oeste Mineiro 


\section{PATROCINADORES}

\section{Ouro}

Nutribody - Dietas e Suplementos Alimentares

MegaScan - Diagnóstico por Imagem

São Geraldo - Drogaria e Manipulação

\section{Prata}

CerterCordis

TechFoot

\section{Bronze}

Academia GoTraining

Corpus Studio

Divus

Instituto Trata

Levi Esportes

Track \& Field

\section{PARCEIROS}

Gráfica Nossa Senhora da Paz

Revista Acervo Mais Saúde

Sociedade Mineira de Medicina do Exercício e do Esporte

Universidade Federal de São João Del Rei 


\section{SUMÁRIO}

TRABALHOS PREMIADOS NO EVENTO.

O EXERCÍCIO FÍSICO COMO AUXÍLIO NO TRATAMENTO DA DEPRESSÃO

FATORES DE RISCO PARA O CÂNCER DE MAMA E A IMPORTÂNCIA DO EXERCÍCIO FÍSICO COMO FATOR PREVENTIVO, COMO PARTE INTEGRANTE DO TRATAMENTO

E PARA SOBREVIVENTES DO CÂNCER DE MAMA.

NUTROLOGIA E SUA RELAÇÃO COM A PERFORMANCE ESPORTIVA NO CROSSFIT: REVISÃO DE LITERATURA

RESUMOS APRESENTADOS NO EVENTO

FREQÜÊNCIA SEMANAL DO TREINAMENTO DE FORÇA E HIPERTROFIA PARA UM GRUPAMENTO MUSCULAR.

RESPOSTA DA PRESSÃO ARTERIAL NO TESTE DE TRÊS QUILÔMETROS TIME TRIAL

EFEITO DO TREINAMENTO AERÓBIO NO ESTADO DE HUMOR DE MULHERES UNIVERSITÁRIAS

A APLICAÇÃO DE VENTOSATERAPIA COMO TÉCNICA COMPLEMENTAR AO TRATAMENTO DE LESÕES MUSCULOESQUELÉTICAS EM ATLETAS

TREINAMENTO DE FORÇA E EMAGRECIMENTO

INFLUÊNCIA DO EXERCÍCIO FÍSICO NO BEM-ESTAR BIOPSICOSSOCIAL DE PACIENTES ONCOLÓGICOS: REVISÃO DE LITERATURA

TRATAMENTO CIRÚRGICO DA DESINSERÇÃO COMPLETA DO TENDÃO DO PEITORAL MAIOR UTILIZANDO ENXERTO DE FÁSCIA LATA - RELATO DE CASO ... 36

A PRÁTICA DE EXERCíCIOS FÍSICOS EM GESTANTES DE ALTO RISCO 38 LESÕES MÚSCULO-ESQUELÉTICAS NO OMBRO DE ATLETAS: UMA REVISÃO BIBLIOGRÁFICA.

PRESENÇA E SEVERIDADE DE INSÔNIA EM PRATICANTES DE EXERCÍCIOS FÍSICOS E INDIVÍDUOS SEDENTÁRIOS: UM COMPARATIVO.

AS VARIÁVEIS DO PROGRAMA DE TREINAMENTO NA MUSCULAÇÃO PARA MELHORA DA PERFORMANCE - UMA REVISÃO BIBLIOGRÁFICA

EXERCÍCIO FÍSICO E AS POSSÍVEIS DOENÇAS ALÉRGICAS ASSOCIADAS À SUA PRÁTICA

ASPECTOS GERAIS DA ABORDAGEM DA MORTE SÚBITA EM ATLETAS

AS VANTAGENS DA INCLUSÃO DO ESPORTE NA VIDA DA POPULAÇÃO IDOSA ..... 49 


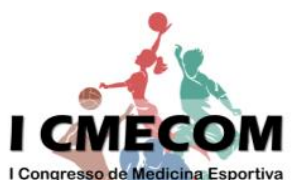

Congresso de Medicina Esportiva do Centro Oeste Mineiro
ANAIS DO I CONGRESSO DE MEDICINA ESPORTIVA DO CENTRO-OESTE MINEIRO

\section{UFS]}

$\mathrm{CCO}$

Campus Centro-Oeste Dona Lindu

A EDUCAÇÃO FÍSICA ESCOLAR PARA A CRIANÇA COM SÍNDROME DE DOWN: A NECESSIDADE DA PREVENÇÃO DE LESÕES DEVIDO À INSTABILIDADE

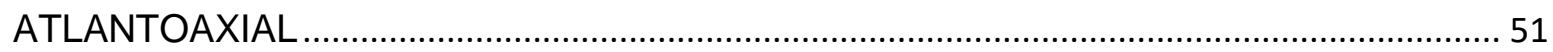

TREINO FUNCIONAL PARA PORTADORES DE SÍNDROME DE DOWN: UM RELATO DE CASO 53

USO DA SUPLEMENTAÇÃO DE CREATINA NA POPULAÇÃO IDOSA. 55 


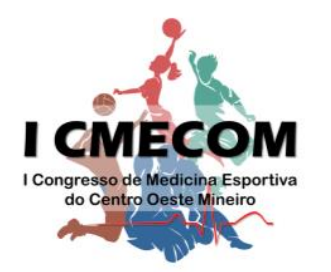

\section{TRABALHOS PREMIADOS NO I CONGRESSO DE MEDICINA ESPORTIVA DO CENTRO-OESTE MINEIRO}




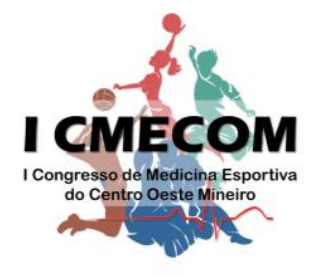

ANAIS DO I CONGRESSO DE MEDICINA ESPORTIVA DO CENTRO-OESTE MINEIRO

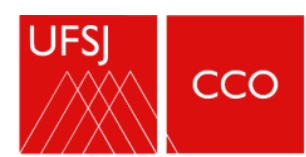

Campus Centro-Oeste Dona Lindu

\section{O EXERCÍ́CIO FíSICO COMO AUXÍLIO NO TRATAMENTO DA DEPRESSÃO}

Ricardo Paulino Coelho, Flavia Borba Paulino Coelho, Lucas Borba Paulino Coelho, Lívia Bárbara Cordeiro Alves, Ana Luiza Pereira de Souza.

Contato: flavia.borbac@gmail.com

Introdução: Segundo a Organização Mundial de Saúde (OMS), a depressão é uma das principais causas de incapacidade no mundo, afetando mais de 300 milhões de pessoas. Nota-se que a maioria dos pacientes procura a atenção primária inicialmente, mas o diagnóstico raramente é feito. (OMS, 2010; American Psychiatric Association, 2014; OMS, 2019). Apesar de ser uma doença amplamente discutida, sua fisiopatologia não é totalmente conhecida. Sabe-se que é uma doença multifatorial evolvendo predisposição genética e estressores ambientais. A teoria monoaminérgica sugere que os níveis das monoaminas estejam diminuídos, alterando a regulação da eficiência do processamento de informações em vários circuitos neuronais, incluindo aspectos emocionais. (TRITSCHLER 2018) O tratamento inicial é realizado com fármacos e psicoterapia. Contudo, em até 33\% dos casos não há remissão mesmo após a 4⿳a etapa do tratamento. Assim, é de interesse a busca por adjuvantes e alternativas ao tratamento convencional da depressão. Dentre esses, figura a prática do exercício físico e diversos estudos têm evidenciado seus benefícios. Assim como os fármacos, promove aumento da concentração de serotonina cerebral e melhora a circulação. (OMS, 2010; American Psychiatric Association, 2014). Objetivos: Realizar uma revisão de literatura sobre o impacto da prática de exercícios físicos na evolução da depressão, focando em resultados. Metodologia: Foram realizadas buscas sistematizadas em bases de dados eletrônicas (MEDLINE/PubMed e SciELO). Os termos utilizados para pesquisa foram "physical exercise" e "depression". Selecionados estudos realizados a partir de 2015. Resultados: Diversos trabalhos evidenciam os benefícios do exercício físico no tratamento da depressão. Um estudo comparativo investigou a combinação de sertralina (S) com duas formas de exercício: aeróbico progressivo (PAE) e aeróbico não progressivo (NPE). Havia também um grupo controle que fazia uso da sertralina isolada. Após 24 semanas de exercícios, os resultados evidenciaram que o grupo tratado com sertralina mais exercícios de ambas as formas obtiveram taxas de remissão maiores e mais rápidas do que o controle tratado apenas com medicamento. "Até o final do estudo, a remissão foi alcançada por $45 \%$ dos participantes do grupo de sertralina, $73 \%$ dos aqueles no grupo S + NPE e $81 \%$ daqueles no grupo $S+P A E(P=0,001)$." (MURRI, et al., 2018). Carneiro et al. (2016) analisaram a relação da enzima catecol-O-metiltransferase com o exercício físico. Essa enzima é moduladora dos níveis dopaminérgicos no córtex pré-frontal, envolvida na degradação das monoaminas. No estudo um grupo de mulheres medicadas foi designado para fazer exercícios físicos, e outro fez uso apenas da medicação. Após 16 semanas os níveis da enzima eram significativamente maiores nos controles $(8.7974 .95 \mathrm{pmol} / \mathrm{mg}$ prot $/ \mathrm{h}$ ) do que nos indivíduos que praticaram o exercício (2.7171.68 pmol/mg prot/h). A conclusão dos pesquisadores foi de que se 0 exercício poderia diminuir os níveis dessa enzima, ele poderia aumentar a 


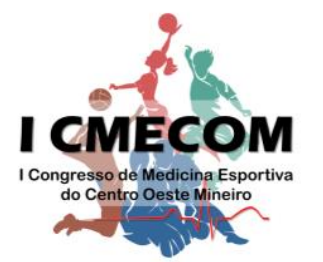

ANAIS DO I CONGRESSO DE MEDICINA ESPORTIVA DO CENTRO-OESTE MINEIRO

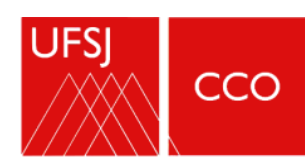

Campus Centro-Oeste

Dona Lindu

disponibilidade de dopamina, o que seria positivo no tratamento da depressão. No entanto, ainda são necessários mais estudos a respeito desse tema, pois o trabalho não avalia a atividade da enzima, apenas a quantidade, não sendo possível inferir que essa redução melhoraria o quadro da depressão. Lavebratt et al. (2017) buscaram identificar os efeitos da prática de exercícios na redução de marcadores inflamatórios, como a interleucina-6 (IL-6), que foi consistentemente relacionada à depressão. Foi analisado o nível de atividade física em pacientes depressivos, além da gravidade da depressão no início e pós-tratamento. Foi investigado também o nível de IL-6 sanguíneo, que foi reavaliado após 12 semanas de exercício físico. Os resultados revelaram que níveis mais altos de IL-6 no início estavam linearmente associados a melhorias na severidade da depressão após o tratamento com exercícios físicos. Além disso, a maior gravidade dos sintomas no início estava associada a reduções maiores nos níveis de IL-6 com a intervenção. Essa descoberta pode ser significativa para pacientes deprimidos com níveis elevados de IL-6, em que o exercício poderia ser muito benéfico. No entanto, são necessárias mais pesquisas para comprovar essa relação. Ainda não há rotinas específicas de exercício que demonstraram melhor eficácia contra a depressão. Porém, uma revisão sistemática demonstrou bom embasamento no uso de exercícios de força de alta intensidade. Além disso, a prática de atividades mistas parece reduzir a depressão, assim como a aeróbica isolada (VILLADA, 2013). Conclusão: A depressão é um problema de saúde pública. O uso de fármacos, apesar de fundamental em grande parte dos casos, não deve ser encarado como um recurso único. O exercício físico apresenta-se como opção complementar ao tratamento, reduzindo a necessidade do uso de múltiplas drogas, além de ter baixo custo. No entanto, a literatura ainda é escassa quanto às modalidades de exercício mais eficazes, ficando o profissional restrito a recomendações gerais.

\section{Referências bibliográficas:}

WORLD HEALTH ORGANIZATION et al. Global recommendations on physical activity for health. World Health Organization, 2010.

\section{WORLD HEALTH ORGANIZATION. Página institucional. Disponível em: https://www.who.int/es/news-room/fact- \\ sheets/detail/depression. Acesso em: 23 out. de 2019.}

American Psychiatric Association. Manual diagnóstico e estatístico de transtornos mentais (DSM V). Porto Alegre: Artmed, 5 ed, 2014.

TRITSCHLER, L. et al. Consequences of the monoaminergic systems cross-talk in the antidepressant activity. L'Encéphale, v. 44 (3), p. 264-273, 2018.
MONTEIRO, Heloísa Mirelle Costa et al. Physical exercise versus fluoxetine: antagonistic effects on cortical spreading depression in Wistar rats. European journal of pharmacology, v. 762, p. 49-54, 2015.

MICHELI, Laura et al. Depression and adult neurogenesis: positive effects of the antidepressant fluoxetine and of physical exercise. Brain research bulletin, 2018.

CARNEIRO, Lara SF et al. Impact of physical exercise on catechol-O-methyltransferase activity in depressive patients: A preliminary communication. Journal of affective disorders, $v$. 193, p. 117-122, 2016.

LAVEBRATT, Catharina et al. Interleukin-6 and depressive symptom severity in response to physical exercise. Psychiatry research, v. 252, p. 270-276, 2017. 


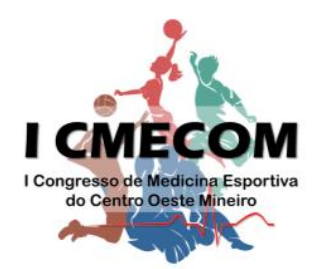

VILLADA, Fredy Alonso Patiño; VÉLEZ, Elkin Fernando Arango; BAENA, Lucidia Zuleta. Ejercicio físico y depresión en adultos mayores: una revisión sistemática. Revista colombiana de Psiquiatría, v. 42, n. 2, p. 198-211, 2013.

DANIELSSON, Louise; KIHLBOM, Birgitta; ROSBERG, Susanne. "Crawling Out of the Cocoon": Patients' Experiences of a Physical Therapy Exercise Intervention in the Treatment of Major Depression. Physical therapy, v. 96, n. 8, p. 1241-1250, 2016.

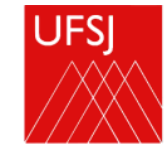

Campus Centro-Oeste Dona Lindu
$\mathrm{SCHUCH}$, Felipe B. et al. Physical activity and incident depression: a meta-analysis of prospective cohort studies. American Journal of Psychiatry, v. 175, n. 7, p. 631-648, 2018.

MURRI, M. Belvederi et al. Physical exercise for late-life major depression. The British Journal of Psychiatry, v. 207, n. 3, p. 235-242, 2015. 


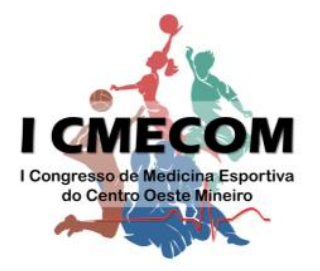

\title{
FATORES DE RISCO PARA O CÂNCER DE MAMA E A IMPORTÂNCIA DO EXERCÍCIO FÍSICO COMO FATOR PREVENTIVO, COMO PARTE INTEGRANTE DO TRATAMENTO E PARA SOBREVIVENTES DO CÂNCER DE MAMA
}

\begin{abstract}
RISK FACTORS FOR BREAST CANCER AND THE IMPORTANCE OF PHYSICAL EXERCISE AS APREVENTIVE FACTOR FOR BREAST CANCER SURVIVORS AS PART OF TREATMENT. FACTORES DE RIESGO PARA EL CÁNCER DE MAMA Y LA IMPORTANCIA DEL EJERCICIO FÍSICOCOMO FACTOR PREVENTIVO PARA LOS SOBREVIVIENTES DE CÁNCER DE MAMA Y COMOPARTE INTEGRAL DEL TRATAMIENTO.
\end{abstract}

\author{
Eduardo Clementino Cruz Flôr, Roberta Lukesevicius Rica, Pedro Augusto Santos \\ Almeida \\ Contato: eduardorf1995@gmail.com
}

\section{RESUMO}

O câncer de mama é o tipo de câncer mais frequente entre mulheres no mundo. Estima-se que no biênio 2018/2019 sejam diagnosticados 59700 casos de câncer de mama no Brasil, uma incidência de 56,33 casos a cada 100 mil mulheres. Objetivo: Investigar os fatores que levam ao câncer de mama e o papel do exercício físico como fator preventivo, como parte integrante do tratamento e como fator importante na melhora da qualidade de vida e longevidade dos sobreviventes do câncer de mama. Métodos: O estudo foi realizado através de uma revisão bibliográfica nas seguintes bases de dados: MEDLINE, LILACS, SciELO e Google Acadêmico, utilizando os termos que relacionavam câncer de mama e exercício físico,foram selecionados artigos da língua inglesa e portuguesa que se enquadravam nos objetivos do trabalho. Resultados: Os principais fatores de risco são idade, ingestão de bebidas alcoólicas, substâncias do meio ambiente, inflamação crônica, dieta, hormônios, imunossupressão, agentes infecciosos, obesidade, radiação e fatores genéticos, o exercício físico mostrou-se efetivo, reduzindo em ate $25 \%$ o risco de câncer da mama, como parte integrante do tratamento, contribuindo para maior taxa de conclusão do mesmo e para os sobreviventes do câncer de mama devido combater os efeitos colaterais do tratamento.

Palavras-chave: Câncer de mama, Exercício Físico, Incidência do Câncer de mama, Prevenção do câncer de mama, Tratamento do câncer de mama e Sobreviventes do câncer de mama.

Divinópolis/MG

2019

\section{SUMMARY}

Breast cancer is the most common type of cancer among women in the world. It is estimated that in 2018/2019, 59700 cases of breast cancer will be diagnosed in Brazil, an incidence of 56.33 cases per 100,000 women. Objective: To investigate the factors that lead to breast cancer and the role of exercise as a preventive factor, as a powerful part of treatment and as an important factor in improving the quality of life and longevity of breast cancer survivors. Methods: The study was conducted through a literature review in the following databases: MEDLINE, LILACS, SciELO and Google Scholar, using the terms that related breast cancer and physical exercise, we selected articles from English and Portuguese that fit the research objectives. Results: The main risk factors are age, alcohol consumption, environmental substances, chronic inflammation, diet, hormones, immunosuppression, infectious agents, obesity, radiation and genetic factors. In all this cases, physical exercise was effective, reducing by up to the $25 \%$ risk of breast cancer as an integral part of the treatment, contributing to its higher completion rate and to breast cancer survivors due to counteracting the side effects of treatment.

Key words: Breast Cancer, Physical Exercise, Breast Cancer Incidence, Breast Cancer Prevention, Breast Cancer Treatment and Breast Cancer Survivors.

\section{RESUMEN}

El cáncer de mama es el tipo de cáncer más común entre las mujeres Del mundo. Se estima que en 2018/2019, se diagnosticarán 59700 casos de cáncer de mama em Brasil, una incidencia de 56.33 casos por cada 100,000 


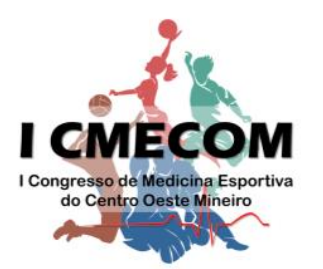

ANAIS DO I CONGRESSO DE MEDICINA ESPORTIVA DO CENTRO-OESTE MINEIRO

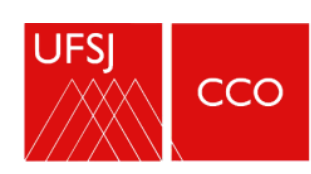

Campus Centro-Oeste

Dona Lindu mujeres. Objetivo: investigar los factores que conducen al cáncer de mama y el papel del ejercicio como factor preventivo, como parte integral del tratamiento y como factor importante para mejorar la calidad de vida y la longevidad de los sobrevivientes de cáncer de mama. Métodos: El estudio se realizó a través de una revisión de la literatura en las siguientes bases de datos: MEDLINE, LILACS, SciELO y Google Scholar, utilizando los términos relacionados con el cáncer de mama y El ejercicio físico, fueron seleccionados artículos de inglés y portugués que se ajustan a los objetivos de trabajo Resultados: Los principales factores de riesgo son edad, consumo de alcohol, sustancias ambientales, inflamación crónica, dieta, hormonas, inmunosupresión, agentes infecciosos, obesidad, radiación y factores genéticos. El ejercicio físico fue efectivo, reduciendo hasta el $25 \%$ de riesgo de cáncer de mama como parte integral del tratamiento, lo que contribuye a su mayor tasa de finalización y a los sobrevivientes de cáncer de mama debido a contrarrestar los efectos secundarios del tratamiento.

Palabras-clave: Cáncer de mama, ejercicio físico, incidencia de cáncer de mama, prevención del cáncer de mama, tratamiento del cáncer de mama y sobrevivientes de cáncer de mama.

INTRODUÇÃO: O câncer de mama que é definido pelo Instituto Nacional de Câncer (INCA) como uma doença causada pela multiplicação desordenada de células da mama, sendo esse processo o gerador de células anormais que se multiplicam, formando um tumor (INCA1). Há vários tipos de câncer de mama, por isso, a doença pode evoluir de diferentes formas, esses comportamentos distintos se devem as características próprias de cada tumor. (INCA3). Em relação a sua incidência, no Brasil segundo o INCA2 estimasse que no biênio 2018/2019, sejam diagnosticados 59700 casos de câncer de mama, com uma estimativa de 56,33 casos a cada 100 mil mulheres (BRASIL, 2017).

Tabela 1- Distribuição proporcional dos dez tipos de câncer mais incidentes para 2018 por sexo, exceto pele não melanoma, INCA, Estimativa 2018 Incidência de Câncer no Brasil.

Distribuição proporcional dos dez tipos de câncer mais incidentes estimados para 2018 por

\begin{tabular}{|c|c|c|c|c|c|c|c|}
\hline Localização Primária & Casos & $\%$ & & & Localizzaçāo Primária & Casos & $\%$ \\
\hline Próstata & 68.220 & $31,7 \%$ & Homens & Mulheres & Mama Feminina & 59.700 & $29,5 \%$ \\
\hline Traqueia, Brônquio e Pulmāo & 18.740 & $8,7 \%$ & & & Cólon e Reto & 18.980 & $9,4 \%$ \\
\hline Estồmago & 13.540 & $6,3 \%$ & & & Traqueia, Brônquio e Pulmão & 12.530 & $6,2 \%$ \\
\hline Cavidade Oral & 11.200 & $5,2 \%$ & & & Glāndula Tireoide & 8.040 & $4,0 \%$ \\
\hline Esôfago & 8.240 & $3,8 \%$ & & & Estômago. & 7.750 & $3,8 \%$ \\
\hline Bexiga & 6.690 & $3,1 \%$ & & & Corpo do Útero & 6.600 & $3,3 \%$ \\
\hline
\end{tabular}

FONTE: INCA, Estimativa, 2018.

MÉTODOS: $O$ estudo foi realizado através de uma revisão bibliográfica nas seguintes bases de dados: MEDLINE, LILACS, SciELO e Google Acadêmico, utilizando os utilizando os termos câncer de mama, exercício físico, incidência do câncer de mama, prevenção do câncer de mama, tratamento do câncer de mama e sobreviventes do câncer de mama, foram selecionados artigos da língua inglesa e portuguesa que se enquadravam nos objetivos do trabalho e que continham uma relevância para pesquisa, foram excluído aqueles trabalhos os quais possuíam uma lacuna em seu método de pesquisa e nos programas de treinamento. RESULTADOS E DISCUSSÃO: O surgimento do câncer de mama de acordo com o National Cancer Institute (2018) está relacionado a um ou vários fatores como o avanço da idade; a ingestão de bebidas alcoólicas; substâncias do meio ambiente; inflamação crônica; alimentação; hormônios; imunossupressão; agentes infecciosos; obesidade; radiação e fatores genéticos. (National Cancer Institute, 2018; Sociedade Americana de 


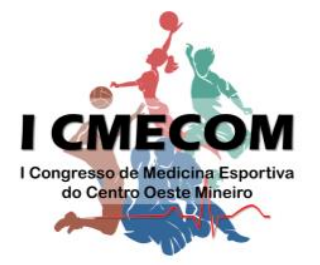

\section{ANAIS DO I CONGRESSO DE MEDICINA ESPORTIVA DO CENTRO-OESTE MINEIRO}

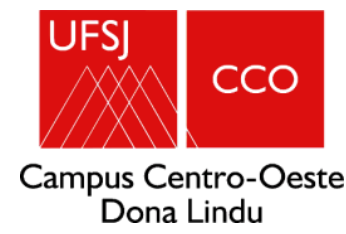

Câncer; 2017). Esses fatores de riscos podem ser amenizados ou até anulados por ações preventivas, entre as quais a prática de exercício físico é considerada evidência forte e consistente para prevenção de alguns tipos de câncer, incluindo o de mama onde temos uma redução do risco em até $25 \%$ de vim a ter esta doença, devido o efeito anti-carcinogênico do exercício físico (Kruk ,2006), outros estudos como os de Suzuki et al.(2008), Hayes et al. (2009), Emi et al. (2011), confirmam o efeito protetivo e mostram que a prevenção é proporcional a quantidade de treinamento. O exercício físico mostra-se efetivo não só na prevenção, mas também durante o tratamento do câncer, segundo Taylor (2004) o exercício físico tem sido consistentemente identificado como um elemento de reabilitação para muitas doenças crônicas e tem obtido sucesso na melhoria da qualidade de vida, na redução da mortalidade por todas as causas, incluindo o câncer de mama. Os tratamentos mais comuns para esta neoplasia malignas incluem um ou mais dos seguintes: nodulectomia, mastectomia, radioterapia, quimioterapia, imunoterapia ou terapia hormonal (SCHMITZ et al., 2010), apesar dessas formas de tratamento serem bem sucedidas, muitas geram efeitos colaterais como náusea, perda de apetite, perda de cabelo, depressão, ganho de peso, dificuldade respiratória, perda de força muscular, fadiga e linfedema (American Cancer Society,2005), que contribuem para um declínio do funcionamento normal de muitos sistemas fisiológicos dos pacientes. Em adultos com câncer de mama um programa de treino composto por exercícios de resistência, aeróbicos e de flexibilidade tem sido associado como muitos benefícios, sendo o mesmo uma forma de intervenção eficaz para melhorar, a aptidão cardiorrespiratória, funcionamento físico, sintomas de fadiga, autoestima, função sexual e composição corporal, além de contribuir para o aumento de força muscular, redução de dores e uma maior taxa de pacientes que conseguem concluir o tratamento (OH et al,.2014; STEINDORF et al., 2014; SHOBEIRI et al.,2016; ADAMS et al., 2016; ZHANG et al., 2019), no geral, todos esses estudos indicam que o treinamento combinado para pacientes com câncer são seguros e benéficos. O programa de treino composto por exercícios de resistência, aeróbicos e de flexibilidade, se mostra de suma importância também para os sobreviventes do câncer mama, muitos dos quais terão uma expectativa de vida normal (Jassemet et al. 2004) e para que isso ocorra um dos principais fatores é a pratica de exercício físico, estima-se que $<10 \%$ dos sobreviventes de câncer estarão ativo durante os tratamentos e apenas $20 \%$ a $30 \%$ destes, estarão ativos após o tratamento(PINTO E CICCOLO, 2011), estima-se que 3 anos após o diagnóstico apenas $32 \%$ dos sobreviventes do câncer de mama mantém os níveis de atividade física habituais(IRWIN et al, 2004). Uma possível razão para as baixas taxas de adesão nessa população é que o interesse, preferências e tolerância ao exercício físico variam entre os sobreviventes de câncer, e há uma necessidade de que o programa de treino atenda e respeite às necessidades e o histórico do indivíduo, portanto, o estado de saúde dos sobreviventes de câncer, tratamentos e trajetórias da doença devem ser considerados para determinar as recomendações de exercício físico para os sobreviventes de câncer (BUFFART et al., 2014), que adquirem com a prática de exercícios físicos benefícios como o controle de peso, a melhora de alguns efeitos colaterais tardios do tratamento que podem vim a aparecer, como linfedema e redução da mobilidade do ombro, efeitos benéficos sobre a angiogênese, moléculas relacionadas à apoptose, qualidade de vida e depressão, escores funcionais e globais 


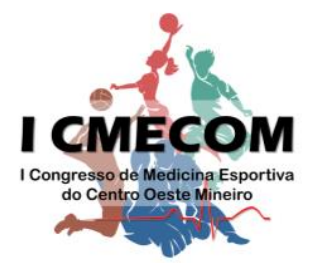

de saúde aumentaram significativamente após o programa de exercícios e reduz a chance de se ter um câncer secundário, em pacientes cujo o tratamento esta completo (ERGUN et al. 2013; GARCIA e THOMSON,2015; SCHMITZ,2010).

Figura 1: Algoritmo sugerido para prescrição de exercícios em pacientes com câncer de mama, uma avaliação de triagem pré-exercício deve ser considerada para pacientes que pretendem iniciar um regime de exercícios regulares, levando em consideração o nível de exercício inicial, as comorbidades e o tratamento do câncer. Consulta adicional deve ser considerada a critério do provedor de tratamento, pacientes que não conhecem o American College of Diretrizes de medicina esportiva (ACSM) devem seguir uma abordagem incremental e gradual para aumentar os níveis de exercício. O objetivo a longo prazo é que realize 20 a 60 minutos de atividade de intensidade moderada a vigorosa pelo menos 5 dias por semana. Treinamento de resistência pode ser considerado uma vez que o nível de exercício alvo é alcançado.

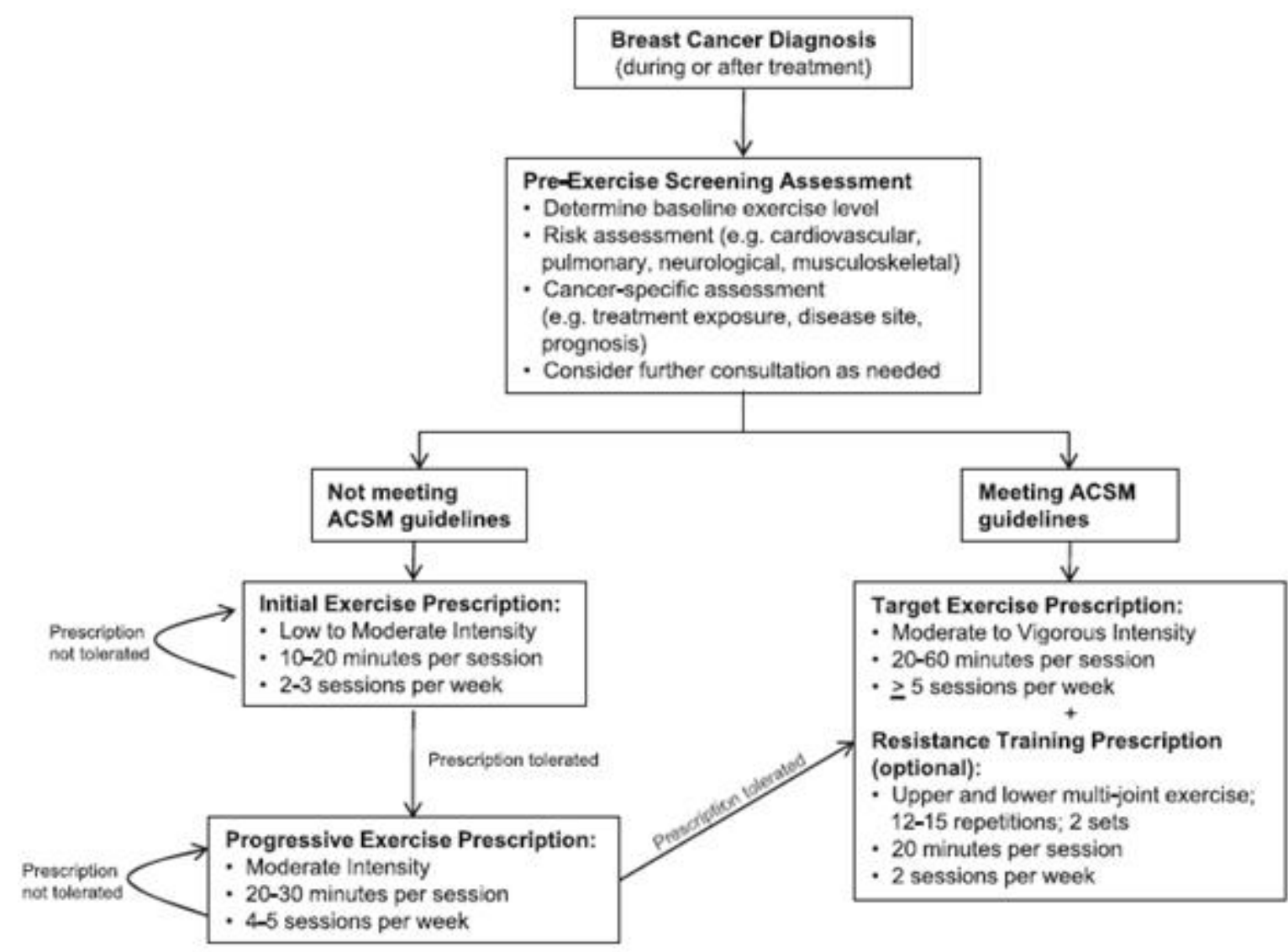

Fonte: Anthonye Lee (2016).

CONCLUSÃO: O exercício físico é uma estratégia efetiva, benéfica, de baixo custo e risco, com poucos efeitos colaterais, sendo importante para a prevenção, tratamento e para os sobreviventes do câncer de mama, contribuindo de forma eficaz e segura para a saúde de forma global, a conclusão do tratamento e o reestabelecimento das funções físicas, psicológicas e sociais. 


\section{ANAIS DO I CONGRESSO DE MEDICINA ESPORTIVA DO CENTRO-OESTE MINEIRO}

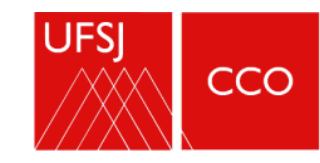

Campus Centro-Oeste

Dona Lindu

\section{REFERÊNCIAS BIBLIOGRÁFICAS}

1. Adams SC, Segal RJ, McKenzie DC, Vallerand JR, Morielli AR, Mackey JR, Gelmon K, Friedenreich CM, Reid RD, Courneya KS; Impact of resistance and aerobic exercise on sarcopenia and dynapenia in breast cancer patients receiving adjuvant chemotherapy:a multicenter randomized controlled trial. Breast Cancer Res Trea, 2016.

2. AMERICAN CANCER SOCIETY. Cancer facts \& figures 2017. Atlanta, 2017. Disponivelem:

$<$ https://www.cancer.org/content/dam/cancerorg/research/cancer-facts-and-statistics/ annual-cancer-facts-and-

figures/2017/cancer-facts-and-figures2017.pdf>. Acesso em:31dez. 2018.

3. Anthony F. Yu and Lee W. Jones. Breast cancer treatment-associated cardiovascular toxicity and effects of exercise countermeasures. Cardio-Oncology, 2016.

4. Berclaz G, Li S, Price KN, Coates AS, Castiglione-Gertsch M, Rudenstam C-M, Holmberg SB, Lindtner J, Eren D, Collins J, Snyder R, Thürlimann B, Fey MF, Mendiola C, Werner ID, Simoncini E, Crivellari D, Gelber RD, Goldhirsch A. Body mass index as a prognostic feature in operable breast cancer: the International Breast Cancer Study Group experience. Ann Oncol 2004; 15:875-884.

5. BRASIL. Ministerio da Saude. Departamento de Informatica do SUS. Sistema de informações sobre mortalidade. Disponivel em: <http://www.datasus.gov.br>. Acesso em:31dez. 2018.

6. BuffartL.M ,Galvão DA, Brug J, ChinapawM.J.M,NewtonR.U,Evidence-based physical activity guidelines for cancer survivors: Current guidelines, knowledge gaps and future research directions, Elselvier, 2014.

7. Calle EE, Rodriguez C, Walker-Thurmond K, Thun MJ. Overweight, obesity, and mortality from cancer in a prospectively studied cohort of U.S. adults. N Engl J Med 2003; 348:16251638.
8. Centers for Disease Control and Prevention. Cancersurvivors-United States, 2007.MMWR Morb Mortal Wkly, acessadoem:https://www.cdc.gov/mmwr/prev iew/mmwrhtml/mm6009a1.htmdia: 17 março 2019, as: $14: 45$.

9. Eml L, Aparecida E, Margareth M. Fatores de risco e de proteção para câncer de mama: uma revisão sistemática. Cad. Saúde Pública, Rio de Janeiro, jul, 2011.

10. Ergun M, Eyigor S, Karaca B, Kisim A, Uslu R (2013) Effects of exercise on angiogenesis and apoptosis-related molecules, qualityof life, fatigue and depression in breast cancer patients. Eur J Cancer.

11. Garcia O, Thomson C. Physical Activity and Cancer Survivorship, Nutrition in Clinical Practice, 2015.

12. Hayes, Sandra C. and Spence, Rosalind R and Galvão, Daniel A and Newton, Robert U Australian Association for Exercise and Sport Science positionstand: optimising cancer outcomes through exercise. Journal of Science and Medicine in Sport, (2009).

13. (INCA) Instituto Nacional De Câncer. Tipos de Câncer, Câncer de Mama 2018, disponível em:www.inca.gov.br/tipos-de-cancer/cancerde-mama acessado em:27 jan. 2013 ${ }^{1}$.

14. INCA). ESTIMATIVA I 2018 Incidência de Câncer no Brasil- Instituto Nacional de Câncer².

15. INCA) Instituto Nacional de Câncer. Ministério da saúde. Prevenção e fatores de risco. Disponível em www.inca.gov.br/causas-eprevencao/prevencao-e-fatores-de-risco acesso em 31 dez 2018.

16. Irwin $M L, M C$ tieman $A$, BernistenIGilliland FD, Baumgartner R, Baumgartner K, ET AL. Physical activity levels amongsbrest cancer survivor. Med Sci Sports exercise.2004.

17. Jassem J, Buchanan M, Janicke F, et al. The Hamburg statement: the partnership driving 
the European agenda on breast cancer. Eur $\mathrm{J}$ Cancer 2004.

18. Kruk J, Aboul-Enein HY. Physical activity in the prevention of cancer. Asian Pac J Cancer Prevent 2006; 7:11-21.

19. Lahmann PH, Friedenreich C, Schuit AJ, Salvini S, Allen NE, Key TJ, et al. Physical activity and breast cancer risk: the European Prospective Investigation into Cancer and Nutrition. Cancer EpidemiolBiomarkersPrev 2007.

20. Leitzmann MF, Moore SC, Peters TM, Lacey Jr. JV, Schatzkin A, Schairer C, et al. Prospective study of physical activity and risk of postmenopausal breast cancer. BreastCancer Res 2008

21. National Cancer Institute(NIH). Cancer causes and Prevention. Disponível em https://www.cancer.gov/about-

cancer/causes-prevention/risk/age acessado em: 31 dez. 2018.

22. Oh BBP, Effects of qigong on quality of life, fatigue, stress, neuropathy, and sexual function in women with metastatic breast. cancer: a feasibility study. J Clin Oncol,2014

23. Peplonska B, Lissowska J, Hartman TJ, Szeszenia- Dabrowska N, Blair A, Zatonski W, et al. Adulthood lifetime physical activity and breast cancer. Epidemiology, 2008.

24. Peters TM, Schatzkin A, Gierach GL, Moore SC, Lacey Jr. JV, Wareham NJ, et al. Physical activity and postmenopausal breast cancer risk in the NIH-AARP diet and health study. Cancer Epidemiol Biomarkers Prev 2009.

25. Pinto BM, Ciccolo JT. Physical activity motivation and cancer survivorship. RecentResultsCancer Res. 2011.

26. Rivlin RS. Nutrition and Cancer Prevention: New Insights into The Role of Phytochemicals. Future directions. AdvExp Med Biol 2001.

27. Schmidt ME, SteindorfK, Mutschelknauss E, Slanger T, Kropp S, Obi N, et al. Physical activityand postmenopausal breast cancer: effect modification by breast cancer subtypes and effective periods in life. CancerEpidemiol Biomarkers Prev2008.

28. Schmitz KH, Couyrneya KS, Matthews C Et al. American College ofSportsMedicineRoundtable on Exercise Guidelines for Cancer Survivors. Official Journal of the American College of Sports Medicine,2010.

29. Shobeiri F, Masoumi SZ, Nikravesh A, HeidariMoghadam R, KaramiM The impact of aerobic exercise on quality of life in women with breast cancer: a randomized controlled trial. J Res Health Sci,2016.

30. Sprague BL, Trentham-Dietz A, Newcomb PA, Titus-Ernstoff L, Hampton JM, Egan KM. Lifetimeand occupational physical activity and risk of in situ and invasive breast cancer. Cancer Epidemiol Biomarkers Prev 2007.

31. Steindorf K, Schmidt ME, Klassen O, Ulrich CM, Oelmann J, Habermann N, Beckhove P, Owen R, Debus J, Wiskemann J, Potthoff $\mathrm{K}$ Randomized, controlled trial of resistance training in breast cancer patients receiving adjuvant radiotherapy: results on cancerrelated fatigue and quality of life. AnnOncol, 2014.

32. Suzuki S, Kojima M, Tokudome S, Mori M, Sakauchi F, Fujino Y, et al. Effect of physical activity on breast cancer risk: findings of the Japan Collaborative Cohort Study. Cancer Epidemiol Biomarkers Prev 2008.

33. Taylor RS, Brown A, Ebrahim S, et al. Exercise-based rehabilitation for patients with coronary heart disease: systematic review and meta-analysis of randomized controlled trials. Am J Med 2004.

34. World Cancer Research Fund/American Institute for Cancer Research. Food, nutrition, physical activity, and the prevention of cancer: a global perspective. Washington DC: American Institute for Cancer Research; 2007, disponível em: www.scielosp.org/pdf/csp/2011.v27n7/12591270/pt, acessado em: 27 jan. 2019

35. World Health Organization. National Cancer Control Programmes: polices and managerial

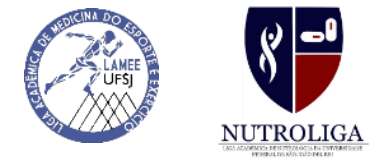




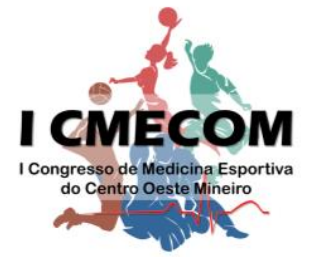

guidelines. 2nd ed. Geneva: WHO; 2002.Pag. 15.
ANAIS DO I CONGRESSO DE MEDICINA ESPORTIVA DO CENTRO-OESTE MINEIRO

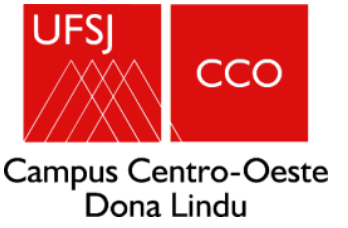

Dona Lindu 


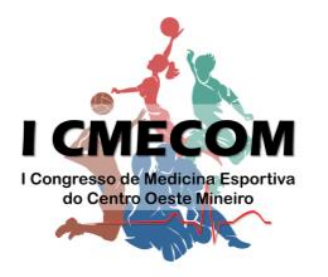

\title{
NUTROLOGIA E SUA RELAÇÃO COM A PERFORMANCE ESPORTIVA NO CROSSFIT: REVISÃO DE LITERATURA
}

\author{
Janete Rabelo Rios, Rodolfo Augusto de Oliveira Mano, Luciana Duarte Pimenta \\ Contato: janeterabelorios2017@gmail.com
}

INTRODUÇÃO: Crossfit é uma modalidade de treinamento que vem ampliando o seu número de praticantes. Reconhecido como treinamento funcional de alta intensidade, se baseia em treinos intervalados associados a levantamento de peso e ginástica. Um dos seus objetivos é o condicionamento físico utilizando os 10 domínios: resistência cardiorrespiratória, resistência muscular, força, flexibilidade, potência, velocidade, coordenação, agilidade, equilibro e precisão. Para tanto, requere equilíbrio das três vias metabólicas (fosfogênica, glicolitica e oxidativa) em sua prática, sendo predominante a via glicolítica na produção de energia. Existem três grupos de macronutrients (proteína, carboidrato e gordura), fundamentais para o funcionamento do organismo, em que os atletas baseiam sua dieta. Durante o exercício, o organismo utiliza duas principais fontes energéticas, o carboidrato e a gordura, já que as proteínas contribuem muito pouco para este processo bioenergético. Este substrato passa por processos bioquímicos até serem convertidos em ATP (trifosfato de adenosina), que é considerado um doador universal de energia para impulsionar os processos celulares, como as contrações musculares. As células musculares dispões de um reservatório muito pequeno de ATP, portanto, durante a atividade física é necessário a reposição rápida e constante destes por meio de uma ou uma combinação das três vias metabólicas. ${ }^{2}$ Dependendo da modalidade esportiva escolhida uma via pode ter a predominância. A escolha de qual será o melhor substrato utilizado está relacionado com a dieta, a intensidade e a duração do exercício, e se o indivíduo passou por treinamento de resistência. Os carboidratos são considerados a melhor fonte primária para exercícios de alta intensidade, já as gorduras para atividades prolongadas de baixa intensidade. Os carboidratos são convertidos em energia pelas vias glicolíticas e oxidativas, tendo como substrato a glicose. Por outro lado, nas gorduras o processo ocorre através de ácidos graxos pela via oxidativa, processo conhecido como gliconeogênese. ${ }^{2},{ }^{3}$ Diante do exposto, devemos correlacionar a dieta e a suplementação a intensidade, volume e duração do exercício para buscar uma melhora na performance esportiva. OBJETIVO: Avaliar as evidências científicas que relacionam a nutrologia e a performance esportiva no Crossfit, utilizando suplementações e estratégias nutricionais a fim de otimizar a performance esportiva dos seus praticantes. METODOLOGIA: Esta revisão de literatura foi realizada no período de Janeiro a Maio de 2019 na base de dados eletrônicos do PubMed. Foram selecionados os termos "Crossfit", "nutrição" e "suplementação", com um total de 122 artigos. Foram incluídos artigos em português e inglês publicados neste período. Sendo excluídos os artigos pagos, num total de 71 artigos com acesso gratuito. Dentre estes foram selecionados 14 artigos relacionados ao tema nutrição e suplementação, objetivo deste trabalho. Os demais artigos foram excluídos por se tratarem de outros temas. Os 14 artigos foram lidos e extraído o mais relevante para discussão. RESULTADOS: Nos estudos realizados com carboidratos houveram melhores resultados no desempenho esportivo, incluindo 0 

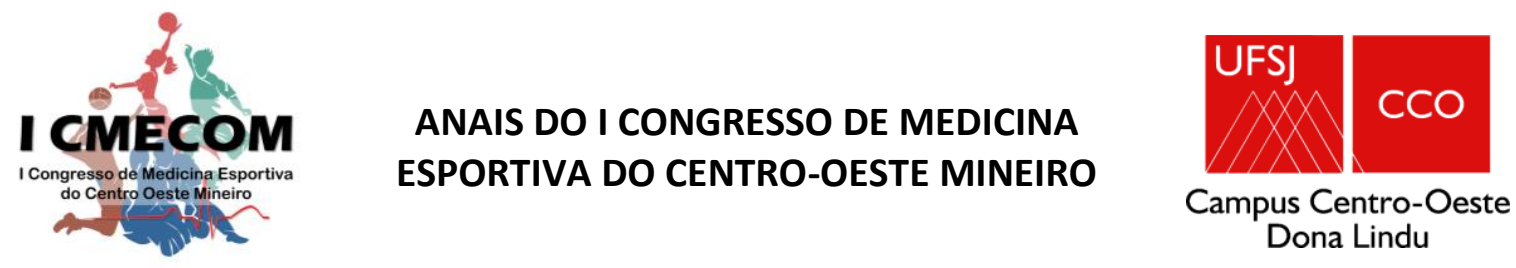

uso de carboidrato e proteína pós treino. De forma análoga, foi observado que o uso de bicarbonato de forma progressiva também proporcionou melhora do desempenho, além de retardar o tempo de limiar ventilatório e apresentar incremento na adaptação corporal dos atletas. Uma vez que, como já estabelecido, exercícios de alta intensidade ocasionam um aumento de lactato e íons hidrogênio dentro da célula, com consequente acidose celular e diminuição da energia, contribuindo para percepção de fadiga. Dessa forma, o bicarbonato contribui para que ocorra o atraso no acúmulo de lactato, portanto da acidose, melhorando rendimento e diminuindo a taxa de degradação glicogênio muscular. Ainda, houveram benefícios com o uso de cafeína, o que se deveu ao seu efeito ergogênico, proporcionando aos atletas aumento do número de repetições e alto volume de exercício, portanto, com melhora da performance esportiva. Por outro lado, os ensaios clínicos com dietas cetogênicas não apresentaram benefícios no desempenho esportivo quando comparados aos citados anteriormente. Apesar de que demonstrou uma leve melhora na composição corporal, a queima de gordura variou de acordo com taxa de VO2, sendo para homens em todas as faixas e para mulheres apenas em taxas de VO2 de alta intensidade. Observou-se também, que o padrão alimentar de praticantes de Crossfit possui planos alimentares com desequilíbrio de macronutrientes, sendo as dietas hiperproteicas e hipolipídicas predominantes entre os adeptos. Além disso, existem ingestão de micronutrientes e suplementação inadequadas, atualmente prejudicando sua performance no esporte.

CONCLUSÃ̃: A escassez de estudos e o padrão dietético apresentada pelos atletas, ressaltam a importância de mais trabalhos e ensaios a respeito da nutrição e performance dos praticantes de Crossfit. Ainda há muito a ser explorado neste sentido, visto que é uma modalidade esportiva relativamente recente, com número crescente de adeptos pelo mundo e que pode se beneficiar da nutrição para um melhor desempenho.

\section{REFERÊNCIAS BIBLIOGRÁFICAS:}

1. Banaszek A, Townsend J, Bender D, Vantrease W, Marshall A, Johnson K. The Effects of Whey vs. Pea Protein on Physical Adaptations Following 8-Weeks of HighIntensity Functional Training (HIFT): A Pilot Study. Sports. 2019 Jan;7(1):12.

2. Scott K. P.; Edward H. T. Fisiologia do exercício: teoria e aplicação ao condicionamento e ao desempenho. $8^{\text {a }}$ edição. Brasil: editora Maneie Ltda, 2014

3. Paschoal V.; Naves Andréia. Tratado de Nutrição Esportiva funcional. 1a edição. Brasil: editora ROCA Ltda, 2014.

4. Kephart W, Pledge C, Roberson P, Mumford P, Romero M, Mobley C, Martin J, Young K, Lowery R, Wilson J, Huggins K. The threemonth effects of a ketogenic diet on body composition, blood parameters, and performance metrics in CrossFit trainees: a pilot study. Sports. 2018 Mar;6(1):1.

5. Stein JA, Ramirez M, Heinrich KM. The Effects of Acute Caffeine Supplementation on Performance in Trained CrossFit Athletes. Sports. 2019 Apr;7(4):95.

6. Kramer SJ, Baur DA, Spicer MT, Vukovich MD, Ormsbee MJ. The effect of six days of dietary nitrate supplementation on performance in trained CrossFit athletes. Journal of the International Society of Sports Nutrition. 2016 Dec;13(1):39.

7. Durkalec-Michalski K, Zawieja EE, Podgórski $\mathrm{T}$, Łoniewski I, Zawieja BE, Warzybok M, Jeszka J. The effect of chronic progressivedose sodium bicarbonate ingestion on CrossFit-like performance: A double-blind, 
randomized cross-over trial. PloS one. 2018 May 17;13(5): e0197480.

8. Escobar KA, Morales J, Vandusseldorp TA. The effect of a moderately low and high carbohydrate intake on crossfit performance. International journal of exercise science. 2016;9(4):460.

9. Oliveira AA, Oliveira AA. Suplementação e performance em praticantes de crossfit. RBNE-Revista Brasileira de Nutrição Esportiva. 2017 Nov 26;11(66):719-23.

10. Maxwell C, Ruth K, Friesen C. Sports nutrition knowledge, perceptions, resources, and advice given by certified CrossFit trainers. Sports. 2017 Jun;5(2):21.

11. Urbina S, Hayward S, Outlaw J, Holt J, Burks $B$, Cox B, Faillace E, Stai B, Stone M, Wildman R, Wells S. Performance and body composition effects of a pre-workout supplement and post-workout protein intake in trained crossfit individuals. Journal of the International Society of Sports Nutrition. 2013 Dec;10(1): P28.

12. Rountree J, Krings B, Peterson T, Thigpen A, McAllister M, Holmes M, Smith J. Efficacy of carbohydrate ingestion on crossfit exercise performance. Sports. 2017 Sep;5(3):61.

13. Sadowska-Krępa E, Domaszewski P, Pokora I, Żebrowska A, Gdańska A, Podgórski T.
Effects of medium-term green tea extract supplementation combined with CrossFit workout on blood antioxidant status and serum brain-derived neurotrophic factor in young men: a pilot study. Journal of the International Society of Sports Nutrition. 2019 Dec;16(1):13.

14. Outlaw JJ, Wilborn CD, Smith-Ryan AE, Hayward SE, Urbina SL, Taylor LW, Foster CA. Effects of a pre-and post-workout proteincarbohydrate supplement in trained crossfit individuals. Springerplus. 2014 Dec $1 ; 3(1): 369$.

15. Durkalec-Michalski K, Nowaczyk PM, Siedzik $\mathrm{K}$. Effect of a four-week ketogenic diet on exercise metabolism in CrossFit-trained athletes. Journal of the International Society of Sports Nutrition. 2019 Dec;16(1):16.

16. Bueno BA, Ribas MR, Bassan JC. Determinação da ingestão de micro e macro nutrientes na dieta de praticantes de Crossfit. RBNE-Revista Brasileira de Nutrição Esportiva. 2016 Aug 8;10(59):579-86.

17. Glassman G. The CrossFit training guide. CrossFit Journal. 2010 May:1-15.

18. Hohl A et al. Suplementos, exercícios e esportes: uma visão endocrinológica / Sociedade Brasileira de Endocrinologia e Metabologia São Paulo: Editora Clannad, 2018 


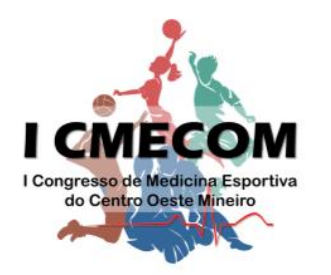

$$
\begin{aligned}
& \text { ANAIS DO I CONGRESSO DE MEDICINA } \\
& \text { ESPORTIVA DO CENTRO-OESTE MINEIRO }
\end{aligned}
$$

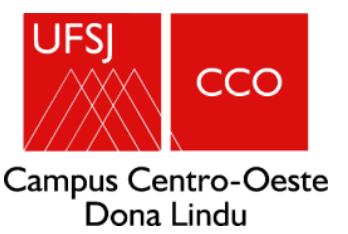

\section{RESUMOS DOS TRABALHOS APRESENTADOS NO I CONGRESSO DE MEDICINA ESPORTIVA DO CENTRO- OESTE MINEIRO}




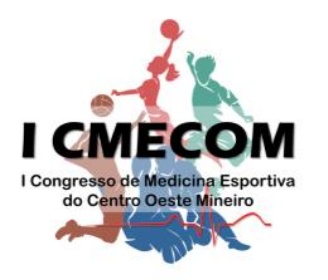

\section{FREQÜÊNCIA SEMANAL DO TREINAMENTO DE FORÇA E HIPERTROFIA PARA UM GRUPAMENTO MUSCULAR}

Juliana Maria Da Costa Menezes, Wendell C. Bila

Contato: jumcmenezes@yahoo.com.br

Introdução: A preocupação com uma melhor qualidade de vida vem fazendo com que as pessoas se importem com a melhoria do condicionamento físico e a musculação tem sido uma escolha bastante popular. A frequência do treinamento se refere ao número de sessões de treinamento realizados em um determinado período de tempo e o número de vezes no qual um grupamento muscular específico é treinado. Diante dos atuais questionamentos quanto à frequência de treino semanal para gerar hipertrofia, é importante reunir elementos que auxiliem o profissional de educação física no momento da montagem do treinamento. Objetivo: Apresentar a um modelo de frequência semanal de treinamentos de força para um mesmo grupamento muscular, capaz de gerar resultados satisfatórios de hipertrofia e força musculares. Metodologia: Revisão bibliográfica narrativa, por meio das bases de dados PubMed Google acadêmico, utilizando-se como filtros os trabalhos publicados nos últimos 5 anos, nos idiomas português, inglês e espanhol, cujas etapas são a leitura dos títulos, análise dos resumos e leitura na íntegra dos artigos selecionados, excluindo-se os artigos repetidos. Resultados: Até o momento foram recrutados 518 trabalhos e permaneceram para compor o presente estudo 22 artigos. O número de vezes que um grupo muscular é treinado semanalmente não tem um impacto significante sobre a hipertrofia em treinos de igual volume, embora possa ser atingida com uma grande frequência semanal de treinamento de resistência, havendo a necessidade de destacar as respostas interindividuais para esta variável. Há evidências de que mesmos protocolos de treinamento de resistência com volumes totais de treinamento não equacionados, a resposta hipertrófica individual possa diferir substancialmente entre os sujeitos, com respostas melhores a maiores volumes de treinamento, mas em alguns casos há a ocorrência de melhores respostas a frequências de treino mais baixas. Observou-se em homens bem treinados a inexistência de diferença significativa de força e hipertrofia para membros inferiores (MMII) e superiores (MMSS) relativas à frequência de treinamento. Alguns trabalhos apresentaram ganhos de força, potência e hipertrofia em MMSS e MMII, especialmente com 12 séries e frequência semanal de 2 vezes. Conclusão: Com base nos estudos analisados, observou-se que protocolos com diferentes frequências de treinamento, mas com volumes equalizados, resultam em Hipertrofia e ganho de força similares. Palavraschave: hipertrofia, frequência de treinamento.

\section{Referências Bibliográficas:}

BRIGATTO, F.A.; BRAZ,

T.C.D.C.; GERMANO,

M.S.; SCHOENFELD,

P.H.; LOPES, C.R. Effect of Resistance Training

Frequency on Neuromuscular Performance and
T.V.;, ZANINI,

M.D.; AOKI,

B.J.; MARCHETTI,

uscle Morphology After 8 Weeks in Trained Men. Journal of Strength and Conditioning Research. 33(8):2104-2116, august 2019
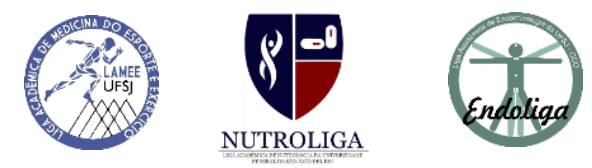


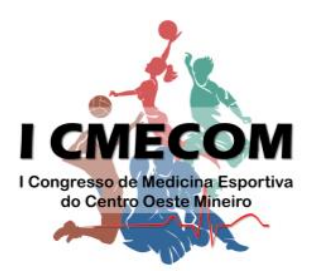

ANAIS DO I CONGRESSO DE MEDICINA ESPORTIVA DO CENTRO-OESTE MINEIRO

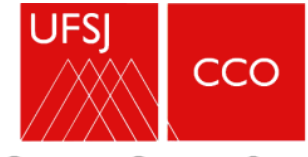

Campus Centro-Oeste Dona Lindu
COLQUHOUN, R.J.; GAI, C.M.; AGUILAR, D.; BOVE, D.; DOLAN, J.; VARGAS, A.; COUVILLION, K.; JENKINS, N.D.M.; CAMPBELL, B.I.. Training Volume, Not Frequency, Indicative of Maximal Strength Adaptations to Resistance Training. Journal of Strength and Conditioning Research. 32(5):12071213, MAY 2018

DAMAS, F., BARCELOS, C., NOBREGA, S. R., UGRINOWITSCH, C., LIXANDRAO, M. E., SANTOS, L. M. E. D., LIBARDI, C. A. (2018). Individual muscle hypertrophy and strength responses to high vs. low resistance training

frequencies. Journal of Strength and Conditioning Research.

GOMES, G. K., FRANCO, C. M., NUNES, P. R. P., \& ORSATTI, F. L. (2018). High frequency resistance training is not more effective than lowfrequency resistance training in increasing muscle mass and strength in well-trained men. Journal of Strength and Conditioning Research.

PRESTES, J., FOSCHINI, D., MARCHETTI, P., CHARRO M., TIBANA, R. (2016). Prescrição e Periodização do Treinamento de Força em Academias. Editora Manole. 2a edição

SARIC, J., LISICA, D., ORLIC, I., GRGIC, J., KRIEGER, J. W., VUK, S., \& SCHOENFELD, B. J.
(2018). Resistance training frequencies of 3 and 6 times per week

produce similar muscular adaptations in resistance-trained men. Journal of Strength and Conditioning Research.

SCHOENFELD, B.J., GRGICB, J., KRIEGERC, J. (2018). How many times per week should a muscle be trained to maximize muscle hypertrophy? A systematic review and metaanalysis of studies examining the effects of resistance training frequency. Journal of Sports Sciences.

YUE, F.L.; KARSTEN, B.; LARUMBE-ZABALA, E.; SEIJO, M.; NACLERIO, F. Comparison of 2 weekly-equalized volume resistance-training routines using different frequencies on body composition and performance in trained males. Applied Physiology Nutrition and Metabolism. 2018 May.

ZARONI, R.S.; BRIGATTO, F.A.; SCHOENFELD, B.J.; BRAZ, T.V.; BENVENUTTI, J.C.; GERMANO, M.D.; MARCHETTI, P.H.; AOKI, M.S.; LOPES; C.R. High Resistance-Training Frequency Enhances Muscle Thickness in Resistance-Trained Men. Journal of Strength and Conditioning Research. 33(): S140-S151, july 2019 


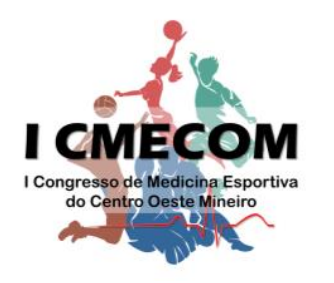

\section{RESPOSTA DA PRESSÃO ARTERIAL NO TESTE DE TRÊS QUILÔMETROS TIME TRIAL}

Isadora Gomes Alves Mariano, Helton Oliveira Campos, José Vítor Vieira Salgado, Fernanda Kelly de Melo, Ana Júlia Dias, Thayane Faveró Silveira, Roseli Silva, Julia Silva, Maria Thereza, João Vítor Gomes, Isabella Carolina Contato: isadoragomesmariano@gmail.com

A obesidade é uma doença de epidemia global caracterizada por excesso de gordura, sendo sua principal etiologia um desequilíbrio energético. A atividade física é um fator primordial para prevenção e tratamento, pois eleva o gasto energético e melhora a capacidade cardiorrespiratória. O objetivo do estudo foi avaliar a resposta da pressão arterial sistólica (PAS) e pressão arterial diastólica (PAD) no teste de três quilômetros $(3 \mathrm{Km})$ time trial em indivíduos obesos. O estudo foi aprovado pelo Comitê de Ética sob número 90396218.0.0000.5115. A amostra foi composta por 72 voluntários, subdivididos em três grupos de acordo com o índice de massa corporal (IMC), sendo respectivamente: normal: IMC $<24,9 \mathrm{~m} / \mathrm{kg}^{2}(\mathrm{n}=34)$; sobrepeso: IMC $>25$ e $<29,9$ $\mathrm{m} / \mathrm{kg}^{2}(\mathrm{n}=25)$ e obeso: IMC $>30 \mathrm{~m} / \mathrm{kg}^{2}(\mathrm{n}=13)$. O teste de $3 \mathrm{~km}$ time trial foi realizado em uma pista plana com 500m. Antes e após o teste foi realizada a mensuração da PAS, PAD e da massa corporal dos voluntários. Para a comparação dos valores de PAS e PAD inicial e final foi realizado o teste $t$ de Student pareado com nível de significância $5 \%$. O grupo composto por pessoas obesas apresentou maior massa corporal (normal: 59,6 $\pm 1,1 \mathrm{~kg}$ vs. sobrepeso: 78,7 $\pm 1,7 \mathrm{~kg}$ vs. obeso: 95,5 $\pm 4,7 \mathrm{~kg}$; $\mathrm{p}<0,05$ ) e IMC (normal: $22,3 \pm 0,3 \mathrm{~kg} \cdot \mathrm{m}^{-2}$ vs. sobrepeso: $27,7 \pm 1,1 \mathrm{~kg} \cdot \mathrm{m}^{-2}$ vs. obeso: $\left.35,8 \pm 1,5 \mathrm{~kg} \cdot \mathrm{m}^{-2} ; \mathrm{p}<0,05\right)$. Foi observado também que, os grupos obesos e sobrepeso apresentaram maior PAS de repouso em comparação ao grupo normal (normal: $108,2 \pm 1,4 \mathrm{mmHg}$ vs. sobrepeso: $116,4 \pm 1,7 \mathrm{mmHg}$ vs. obeso: $122,3 \pm 4,4$ $\mathrm{mmHg} ; \mathrm{p}<0,05)$. Além disso, o grupo obeso apresentou um menor desempenho físico em comparação aos demais grupos (normal: $27,0 \pm 0,6$ min vs. sobrepeso: $21,3 \pm 1,1$ min vs. obeso: $25,9 \pm 0,9 \mathrm{~min} ; \mathrm{p}<0,05)$. No teste de $3 \mathrm{~km}$ time trial foi a amostra com maior PAD inicial (normal: $68,5 \pm 1,3 \mathrm{mmHg}$ vs. sobrepeso: $72,0 \pm 1,4 \mathrm{mmHg}$ vs. obeso: 79,0 $\pm 2,6 \mathrm{mmHg}$; $\mathrm{p}<0,05$ ) e final (normal: $72,5 \pm 2,1 \mathrm{mmHg}$ vs. sobrepeso: $75,2 \pm 2,8 \mathrm{mmHg}$ vs. obeso: $81,5 \pm 4,0 \mathrm{mmHg} ; \mathrm{p}<0,05$ ), e maior PAS inicial (normal: $107,5 \pm 1,7 \mathrm{mmHg}$ vs. sobrepeso: $112,8 \pm 1,5 \mathrm{mmHg}$ vs. obeso: $121,5 \pm 5,0 \mathrm{mmHg}$; $\mathrm{p}$ $<0,05$ ) e final (normal: $135,2 \pm 2,3 \mathrm{mmHg}$ vs. sobrepeso: $138,8 \pm 3,0 \mathrm{mmHg}$ vs. obeso: $146,1 \pm 5,2 \mathrm{mmHg} ; \mathrm{p}<0,05)$. Durante o teste $3 \mathrm{~km}$ time trial não houve aumento da PAD em nenhum dos tratamentos avaliados $(p>0,05)$. Além disso, durante o teste houve aumento da PAS em todos os 3 grupos $(p<0,05)$. Baseando se nos resultados, conclui-se que o grupo obeso apresentou menor desempenho físico e maior PAS e PAD.

\section{Referências Bibliográficas:}

Stevens GA, Singh GM, Lu Y, et al. National, regional, and global trends in adult overweight and obesity prevalences. Popul Health Metr. 2012; 10:22. [PubMed: 23167948]
Ng M, Fleming T, Robinson M, Thomson B. Graetz N, Margono C, et al. Global, regional e prevalência nacional de excesso de peso e obesidade em crianças e adultos durante 1980-2013: análise 

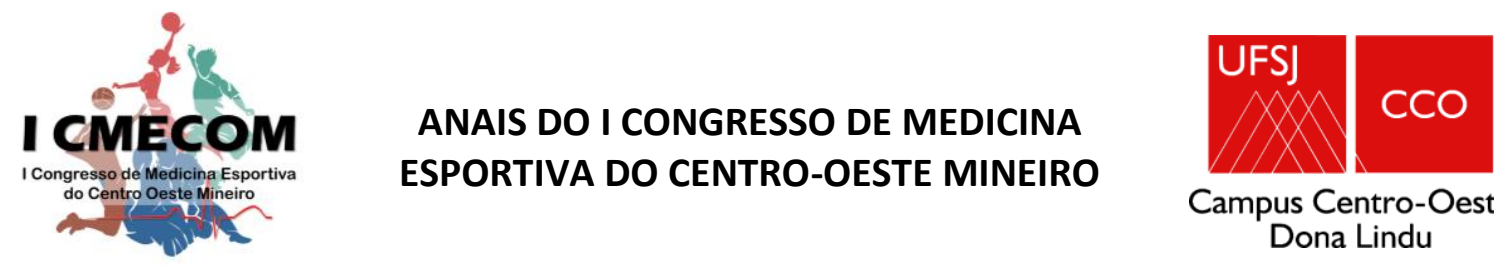

Campus Centro-Oeste Dona Lindu

sistemática para o estudo Global Burden of Disease Study 2013. Lancet. 2014; 384: 766-781.

Faerstein E, Chor D, Griep RH, Alves MG, Werneck GL, Lopes CS. Aferição da pressão arterial: experiência de treinamento de pessoal e controle de qualidade no Estudo Pró-Saúde. Cad Saúde Pública 2006; 22:1997-2002.

Classificação da obesidade no adulto em função do IMC e risco de Comorbilidades (Programa Nacional de Combate à Obesidade - 2005). 


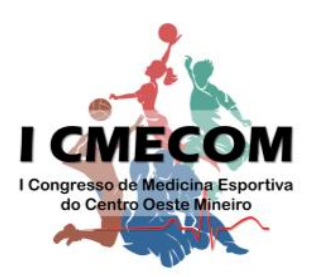

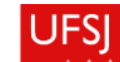

$\mathrm{CCO}$

Campus Centro-Oeste

Dona Lindu

\section{EFEITO DO TREINAMENTO AERÓBIO NO ESTADO DE HUMOR DE MULHERES UNIVERSITÁRIAS}

Isabella Carolina Silva Pereira, Valéria Cristina De Faria, Isadora Gomes Alves Mariano, Ana Júlia Dias, João Vítor Gomes, Fernanda Kelly De Melo, Thayane Fávero Silveira, Roseli Silva De Oliveira, Julia Vieira Salgado Silva, Maria Thereza De Oliveira Almeida, José Vítor Vieira Salgado

Contato: isabellacarolinaef@hotmail.com

O exercício físico proporciona vários benefícios para a promoção da qualidade de vida de um indivíduo. Um estilo de vida ativo associado a esta prática regular é um método eficaz na redução de riscos de doenças cardiovasculares, câncer, diabetes, obesidade e hipertensão arterial, como também, a fatores psicológicos, sociais e ambientais. $O$ objetivo do estudo foi avaliar o efeito do treinamento aeróbio relacionado ao estado de humor de mulheres universitárias participantes de um projeto de extensão. $O$ estudo foi aprovado pelo Comitê de Ética em Pesquisas com Seres Humanos sob número 90396218.0.0000.5115. A amostra foi composta por 11 universitárias com média de idade de $31,18 \pm 11,37$ anos. Os avaliados inicialmente receberam autorização médica para a prática de exercícios físicos, em seguida houve a aplicação da Escala de Humor de Brunel para a mensuração do estado de humor. Após 11 semanas de treinamento aeróbio o questionário foi reaplicado. O treinamento aeróbio ocorreu 3 vezes na semana com duração total de 60 minutos. Cada sessão de treinamento foi dívida em 3 momentos: aquecimento, parte principal e alongamento. A intensidade do exercício aeróbio foi estimada pela escala de Borg. A progressão da carga foi de um incremento de $10 \%$ do volume a cada semana de treinamento proposto. A distribuição dos dados foi verificada pelo teste Shapiro-Wilk e pela análise dos gráficos histograma e Q-Q plot. Na estatística descritiva foram adotados os valores de mediana e do $1^{\circ}$ e $3^{\circ}$ quartil, como valores de tendência central e dispersão, respectivamente. Na estatística inferencial foi utilizado o teste de Wilcoxon para comparar os valores pré e pós intervenção. O nível de significância adotado foi de $5 \%$ e para análise dos dados foi utilizado o programa SPSS 2.5. Os resultados demonstram que houve o aumento para as dimensões raiva, confusão e depressão e diminuição para as dimensões fadiga, tensão e vigor, entretanto não apresentaram resultados significativos. Conclui-se que para o efeito do exercício aeróbio durante 11 semanas de treinamento relacionado ao estado de humor não houve diferença significativa para nenhuma das dimensões. No entanto foi observado que no período de reaplicação do questionário as participantes estavam realizando provas finais na universidade, o que pode ter interferido nos resultados e este fato pode ser uma limitação do estudo. Portanto, futuras pesquisas devem ser realizadas.

\section{Referências Bibliográficas:}

BRANDT, Ricardo et al. Relações entre os estados de humor e o desempenho esportivo de velejadores de alto nível. Psicologia: Teoria e
Prática, Florianópolis, v. 13, n. 1, p.117-130, mar. 2011 
MELLO, Marco Túlio de et al. O exercício físico e os aspectos psicobiológicos. Ver Bras Med Esporte, São Paulo, v. 11, n. 3, p.203-207, jun. 2005

ROHLFS, Izabel Cristina Provenza de Miranda. Validação do teste BRUMS para a avaliação de humor em atletas e não atletas brasileiros. 2006. 110 f. Dissertação (Mestrado) Curso de Centro de Educação Física Fisioterapia e Desporto, Universidade do Estado de Santa Catarina, Florianópolis, 2006
SILVA, Paulo Sérgio Barros da; FERREIRA, Carlos Ernesto Santos. Exercício físico e humor: uma revisão acerca do tema. Educação Física em Revista, Brasília, v. 5, n. 3, p.1-8, dez. 2011.

VIEIRA, Lenamar Fiorese et al., Estado de humor e periodização de treinamento: um estudo com atletas fundistas de alto rendimento. $R$. da Educação Física, Maringa, v. 21, n. 4, p.585-591, maio 2010 


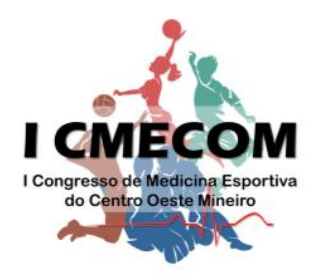

\section{A APLICAÇÃO DE VENTOSATERAPIA COMO TÉCNICA COMPLEMENTAR AO TRATAMENTO DE LESÕES MUSCULOESQUELÉTICAS EM ATLETAS}

William Alves Bueno, Moisés Fiúsa Menezes, Bruna Teixeira Costa. Laila Nathieline Gonçalves Rodrigues Madureira, Maria Luiza Correia da Silva

Contato: moisesfiusa4@gmail.com

Introdução: A busca pela melhoria da técnica e performance no esporte durante as competições levam os atletas a realizarem treinos exaustivos que tem como consequências fadigas, distensões musculares, câimbras, estiramentos entre outras lesões $^{12}$. A prevenção e tratamento dessas lesões são prioridades, pois uma falha no tratamento pode levar a cronificação da lesão e da dor sentida pelo atleta1 ${ }^{1}$. Visando a prevenção, a recuperação de lesões e a diminuição da medicalização, tem crescido o uso de práticas integrativas e complementares, em especial, os recursos da Medicina Tradicional Chinesa (MTC) em atletas ${ }^{3}$. Entre as práticas da MTC, destaca-se a ventosaterapia, uma técnica que consiste na aplicação de copos, de diferentes materiais, em um acuponto ou área de dor, mediante vácuo associado ou não ao calor $^{3} 4$. Objetivo: Conhecer, por meio da literatura científica, as contribuições do uso da ventosaterapia como técnica complementar ao tratamento de lesões musculoesqueléticas em atletas. Materiais e métodos: Foi realizado busca na plataforma da Biblioteca Virtual em Saúde em Medicinas Tradicionais, Complementares e Integrativas (BVS MTCI), utilizando os termos: Medicina Tradicional Chinesa, Medicina Desportiva, Atletas, Ventosas, todos estes em língua portuguesa e inglesa. A busca ocorreu em agosto de 2019, sem considerar a data de publicação dos estudos e tendo como critério de elegibilidade o uso da técnica de ventosaterapia em atletas. Resultados: Foram encontrados artigos relacionados ao uso ventosaterapia como método terapêutico no tratamento da dor muscular e prevenção de lesões em atletas, através do estímulo da circulação sanguínea, nutrição dos músculos, alívio de tensão, alívio das dores e redução da fadiga que atinge os atletas após a prática das atividades físicas ${ }^{256}$. Em geral, o uso de desta técnica se mostrou uma terapêutica complementar eficaz no tratamento de lesões em atletas, sendo eficiente principalmente no controle da dor e diminuição da fadiga muscular ${ }^{1256}$. Observou-se que há poucos estudos realizados, com uma variabilidade metodológica e poucos ensaios clínicos randomizados, o que compromete o rigor dos resultados. Conclusão: Os estudos revistos apresentam a ventosaterapia como terapêutica complementar promissora. Todavia, nota-se uma escassez de estudos nessa temática, sobretudo realizados no Brasil, o que apresenta um campo promissor de pesquisa a ser explorado, principalmente no que tange ao uso de critérios científicos com maior rigor metodológico. Nesse sentido, as evidências científicas são positivas ao uso da ventosaterapia, porém estudos com ênfase em atletas, ainda são um desafio para que a técnica possa ser melhor empregada, diminuindo assim o uso excessivo de analgésicos, relaxantes musculares e anti-inflamatórios. 


\section{Referências Bibliográficas:}

1. Pereira GP, Souza FGL. A importância da acupuntura em lesões desportivas de ombro. Goiânia. Tese [Especialização em Acupuntura] Faculdade Ávila; 2017.

2. Tarek S. Effects of cupping therapy based on stabilization core exercises on low back pain for soccer players in State of United Arab Emirates. Sci Mov and Health. Set 2016; 16(2): 684-690.

3.Santos VC, Kawano MM, Banja RA. Acupuntura na melhora da performance em atletas juvenis de handebol. Rev Saúde e Pes. Set-Dez 2008; 1(3): 331-335.
4.Cunha AA. Ventosaterapia. 2 ed. São Paulo: Icone;1996.

5. Moura CC, Chaves ECL, Cardoso ACLR, Nogueira DA, Correa HP, Chianca TCM. Ventosaterapia e dor crônica nas costas: revisão sistemática e metánalise. Re. Latino-Am Enfer. 2018; 26(e)3094.

6. Li T, Li Y, Lin Y, Li K. Significant and sustaining elevation of blood oxygen induced by Chinese cuppin therapy as assessed by near-infrared spectroscopy. Bio Opt Expr. Nov 2016; 8(1): 223229. 


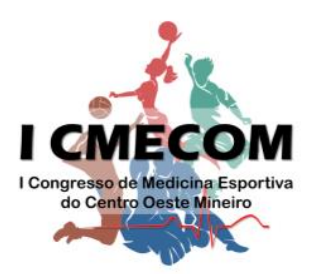

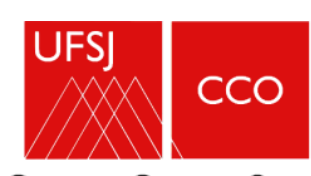

Campus Centro-Oeste

Dona Lindu

\title{
TREINAMENTO DE FORÇA E EMAGRECIMENTO
}

\author{
Marlon Alexandre Chaves \\ Contato: marlon2810@hotmail.com
}

Considerada como uma Doença Crônica Não Transmissível (DCNT), a obesidade é caracterizada pelo acúmulo de gordura no tecido adiposo e aparece como um dos mais graves problemas de saúde pública da atualidade. Diversos fatores podem estar relacionados; dentre eles o sedentarismo, mudanças de hábitos alimentares como a inserção descontroladas de açucares simples, gorduras saturadas e alimentos industrializados, faz-se necessário que medidas sejam tomadas visto que a mesma está diretamente relacionada a inúmeras doenças. A prevenção e controle é o objetivo deste estudo demonstrando que a prática de atividades físicas em específico o treinamento resistido, atua em conjunto a outros fatores para diminuição da porcentagem de gordura e aumento da massa magra resultando em um emagrecimento saudável. Foi realizado um levantamento bibliográfico nas bases de dados Scielo, PubMed, Portal de Periódicos da Coordenação de Aperfeiçoamento de Pessoal de Nível Superior (CAPES); Portal da Educação; Revista Brasileira de Medicina do Esporte; Revista Brasileira de Prescrição de Exercício e Fisiologia do Exercício (RBPFEX) e busca de dados no Google Acadêmico de artigos científicos publicados até 2017. Algumas modalidades de atividade física podem ter efeitos mais benéficos que outras em relação ao impacto sobre o balanço energético, a prescrição da atividade física para o emagrecimento restringia aos exercícios aeróbios, não levando em consideração a massa corporal magra e o metabolismo de repouso. Em meados da década de 80 ACMS (Colégio Americano de Medicina do Esporte) juntamente com a comunidade científica reconheceu o potencial valor do treinamento com pesos sobre a capacidade funcional e outros fatores relacionados à saúde. Um dos motivos pelos quais o treinamento resistido foi incluído nos programas de emagrecimento. Através dessa revisão, os resultados apresentados evidenciam que o treinamento resistido juntamente com uma dieta alimentar balanceada foi o mais eficiente para promover ótimos resultados para um emagrecimento seguro e saudável. Há também de se observar que a intensidade da atividade física parece estar diretamente relacionada com o emagrecimento, quanto maior a intensidade maior a queima calórica durante e após a atividade. Nossos achados demonstraram que o treinamento resistido surge como uma ferramenta exequível e de baixo custo no combate a obesidade. Vale salientar que este tipo de intervenção sempre deve ser prescrito por um profissional capacitado, uma vez que o mesmo possui inúmeras variáveis disponíveis para adaptar e motivar seu cliente, respeitando assim, a sua individualidade biológica.

\section{Referências Bibliográficas:}

ACMS, American College of Sports Medicine. Position stand: progression models in

resistance training for healthy adults. Med Sci Sports Exerc. 2002 N. 34 p. 364 a 380
BAHR R.; Sejersted O.M. Effect of feeding and fasting on excess postexercise

oxygen consumption. J Appl Physiol. 71(6):2088-93 1991.

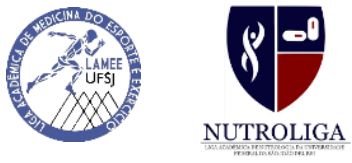




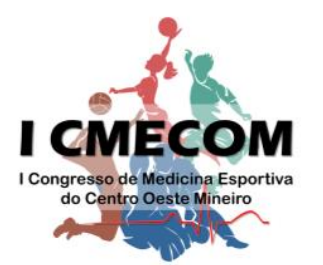

BROEDER et al. The effects of either highintensity resistance or endurance

training on resting metabolic rate. American Journal of Clinical Nutrition v.55, n.4

802-810 apr.1992.

CAMPBELL W.W; Crim M. C.; Young, V.R.; Evans, W.J. Increased energy

requirements and changes in body composition resistance training in older

adults. A. Soc. Clin. Nutr. V. 60, 1994, p.167-175.

COUTINHO M.; Lucatelli M. Produção científica em nutrição e percepção pública da fome e alimentação no Brasil. Revista de Saúde Pública. SciELO Public Health 2006.

DAMASO, A. Obesidade. Exercício e metabolismo energético. Rio de Janeiro.

Editora Guanabara Koogan 2003 p. 257-287

DAMASO, A. Obesidade. Patologias Associadas a Obesidade. Rio de Janeiro.

Editora Guanabara Koogan. 2003 p. 33 a 101

Fernandez, A.C. Influência do treinamento aeróbio e anaeróbio na massa de corporal de adolescentes obesos. Revista Brasileira de Medicina do

Esporte. São Paulo, v.10, n.3, maio/jun. 2004.

FLECK, S.J.; Kraemer, W.J. Fundamentos do Treinamento de Força Muscular. 4a edição. Porto Alegre: Editora Artmed. 2006

GENTIL, P. Emagrecimento - Quebrando Mitos e Paradigmas. Rio de Janeiro.

Editora Sprint, 2011.

GORE C.J.; Withers R.T. Effect of exercise intensity and duration on

postexercise metabolism. J Appl Physiol. 1990;68(6):2362-8

GUEDES, D.P.; Souza, T.P.; Rocha, A.C. Treinamento Personalizado em

Musculação. 1 a edição. São Paulo: Editora Phorte. 2008 p. 87 a 88
HAUSER C.; Benetti M.; Fabiana P. V. R. Estratégias para o Emagrecimento.

Revista Brasileira Cineantropometria e Desempenho Humano. v.6 n(1). 2004 p. 72 a

81

HUNTER G.R.; Weinsier R.L.; Bamman, M.M.; Larson D.E. A role for high intensity

exercise on energy balance and weight control. Int J Obes. 1998;22:489-93.

HUNTER G. R.; Wetzstein C. J.; Fields D.A.; Brown A.; Mamman M. M. Resistance

training increases total energy expenditure and free-living physical activity in

older adults. The American Physiological Society. n.89 p. 977-984 2000.

Krammer W.J.; Volek J.S.; Clark K.L.; Gordon S.E.; Puhl S.M.; Koziris L.P.; Mcbride

J.M.; Triplett-Mcbride N.T.; Putukian M.; Newton R.U.; Hakkinen K.; Bush J.A.;

Sebastianelli W.J. Influence of exercise training on physiological and

performance changes with weight loss in men. Med Sci Sports Exerc.

1999;)31:1320 a 1329

LERARIO, A. C.; LOTTENBERG, S. A. Mecanismos ambientais implicados no ganho de peso e as oportunidades para prevenção da obesidade. Einstein. 2006; Supl. 1: S7-S13

Lima-Silva A.E.; Pires F.O.; Bertuzzi R. Excesso de oxigênio consumido pós esforço: Possíveis mecanismos Fisiológicos. Reveducfis. 2010;21(3):563-75.

LIMA R.M. Obesidade, o mal do século. Revista Perspectiva Online. 2007 1(2): p. 86 a 99

LORENZI, D. R. S.; Basso, E.; Fagundes P. O.; Saciloto, B. Prevalência de sobrepeso e obesidade no climatério. Revista Brasileira de Ginecologia e Obstetrícia, vol.27 n.8 Rio de Janeiro Agosto 2005 


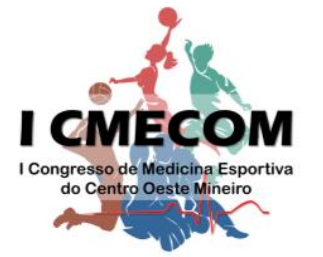

MAIOR, A.S. Fisiologia dos exercícios resistidos. $2^{a}$ edição. São Paulo: Editora Phorte. 2003 p. 17 a 20

MCARDLLE, W.D.; Katch, F.I., Katch, V.L. Fisiologia do Exercício. Energia, Nutrição e Desempenho humano. $8^{\text {a }}$ edição. Rio de Janeiro. Editora Guanabara Koogan. 2016 p. 817 a 858

Melby C.; Scholl C.; Edwards G.; et al. Effect of acute resistance exercise on post

exercise energy expenditure and resting metabolic rate. Journal of Applied

Physiology, v.75, n.4, p.1847-1953, oct.1993.

PINHEIRO, A. R. O.; Freitas, S. F. T.; Corso A. C. T. Uma abordagem epidemiológica da obesidade. Revista de Nutrição. Campinas, v.17, n.4, 2004 p. 523 a 533

PINTO R. S.; Lupi R.; Brentano M.A. Respostas metabólicas ao treinamento de força: uma ênfase no dispêndio energético. Revista Brasileira Cineantropometria e Desempenho Humano. 13(2): 150-7 2011.

PRESTES, J.; Foschini, D.; Marchetti, P.; Charro M.A.; Tibana, R.A. Prescrição e Periodização do
Treinamento de Força em Academias. $2^{\mathrm{a}}$ edição. São Paulo. Editora Manole 2016 p. 30 a 35

SALE, D.G. Influence of exercise and training on motor unit activation. Exercise and Sport Sciences Review, v.15, p.95-149, 1987.

SALVE M. G. C. Obesidade e peso corporal: riscos e consequências. Revista Movimento e Percepção. v.6 2006. p. 29 a 48

SANTAREM, J. M. Musculação em todas as idades: comece a praticar antes que seu médico recomende. Barueri. Editora Manole 2012.

Silva, M.S. Efeitos do treinamento intervalado na redução da gordura corporal em mulheres adultas. Revista Digital. Buenos Aires, ano 10, N. 70. Março, 2004.

Teixeira AV, Rocha GM. Efeito de um protocolo de treinamento de força periodizado sobre a composição corporal de mulheres com idades entre 50 e 60 anos. RBPFEX. 2014;8(44)

XAVIER B. M. L. S. Fatores relacionados à obesidade infantil [trabalho de conclusão de curso]. Valparaiso: Faculdade de Ciências da Educação Sena Aires; 2014 


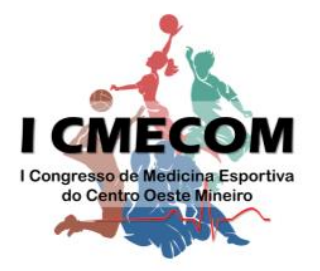

\section{INFLUÊNCIA DO EXERCÍCIO FÍSICO NO BEM-ESTAR BIOPSICOSSOCIAL DE PACIENTES ONCOLÓGICOS: REVISÃO DE LITERATURA}

Lorenza Caser, Amanda Hayeck, Thamyres Figueredo, Laissa Tavares

Contato: lorenza caser@hotmail.com

INTRODUÇÃO: Observa-se um aumento significativo na incidência do câncer, que é uma doença com um impacto negativo no bem-estar do paciente. Identificar maneiras modificáveis e práticas de reduzir o impacto tanto da doença, quanto do tratamento a curto e a longo prazo é uma prioridade de saúde pública. O reconhecimento do exercício físico (EF) como benéfico para a saúde e bem-estar de pessoas com doenças crônicas e comorbidades, suscitou-se um forte interesse na associação entre o papel do EF e a qualidade de vida de pacientes oncológicos. OBJETIVO: Avaliar a influência do EF na qualidade de vida de pacientes oncológicos durante e após o tratamento. MATERIAIS E METODOS: Realizou-se uma revisão de literatura através da plataforma Pubmed, LILACS e BIREME usando os termos de busca como "physical exercise" OR "physical activity" OR "atividade física" OR "exercício físico" OR "exercice" AND (Cancer OR tumor OR oncology). Utilizou-se como critério de inclusão estudos em inglês publicados de 2008 a 2019. Selecionou-se um total de 19 artigos, sendo estes revisão, metanálise ou coorte. RESULTADOS E DISCUSSÂO: Estudos epidemiológicos demonstraram que realizar EF reduz a incidência de pelo menos 13 tipos diferentes de câncer e, fornece evidência da redução de recidiva do câncer de mama, cólon e próstata. A literatura mostrara que o EF controla a progressão do câncer através de efeitos diretos sobre fatores intrínsecos do tumor, alivia eventos adversos relacionados ao câncer e seu tratamento, melhora a eficácia dos tratamentos e diminui risco de recidivas e mortalidade. O EF promove a mobilização e redistribuição de células imunitárias citotóxicas através do aumento dos níveis de quimiocinas imuno-atratentes, ligantes do receptor de ativação das células NK e ligantes do bloqueio do ponto de verificação imune, acarretando na diminuição do crescimento do tumor. Além disso, o EF contribui para a diminuição do nível de senescência celular, gera fatores extrínsecos os quais têm o potencial de regular a cinética do crescimento tumoral e reduz os níveis de lactato intracelular. Diversos estudos mostraram impacto positivo do EF no condicionamento, autoestima, diminuição da fadiga e recuperação mais rápida. CONCLUSÃO: Percebeu-se uma convergência dos dados da literatura demonstrando o efeito benéfico da prática de $E F$ em pacientes oncológicos.

\section{REFERÊNCIAS BIBLIOGRÁFICAS}

BATTAGLINI CL, MILLS RC, PHILLIPS BL, et al. Twenty-five years of research on the effects of exercise training in breast cancer survivors: a systematic review of the literature. World $\mathrm{J}$ Clin Oncol. 2014;5(2):177-90. http://www.pubmedcentral.nih.gov/articlerender.fc gi $?$ artid=4014791\&tool=pmcentrez\&rendertype $=a$ bstract.

BLAND, Kelcey A. et al. Impact of exercise on chemotherapy completion rate: A systematic review of the evidence and recommendations 


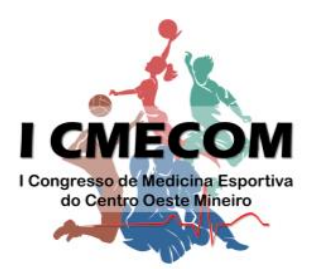

ANAIS DO I CONGRESSO DE MEDICINA ESPORTIVA DO CENTRO-OESTE MINEIRO

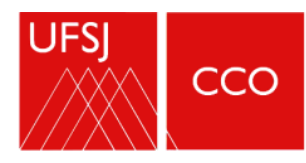

Campus Centro-Oeste

Dona Lindu for future exercise oncology research. Critical Reviews in Oncology/Hematology v. 136, p. 7985 , 1 abr. 2019. Disponível em: <https://www.sciencedirect.com/science/article/a bs/pii/S1040842818304797>.

JONNA K. van Vulpen, PETER D. Siersema, et al. Physical exercise following esophageal cancer treatment (perfect) study: design of a randomized controlled trial. BMC Cancer. 2017. 17:552. DOI 10.1186/s12885-017-3542-8

HOJMAN P, Gehl J, CHRISTENSEN JF, PEDERSEN BK. Molecular mechanisms linking exercise to cancer prevention and treatment. Cell Metab. 2018 Jan 9;27:10-21. doi: 10.1016/j.cmet.2017.09.015.

KILARI, Deepak et al. Designing exercise clinical trials for older adults with cancer: Recommendations from 2015 Cancer and Aging Research Group NCl U13 Meeting. Journal of Geriatric Oncology v. 7, n. 4, p. 293304 , jul. 2016. Disponível em: $<$ https://linkinghub.elsevier.com/retrieve/pii/S187 9406816300339>.

LUCTKAR-FLUDE, Marian et al. Fatigue and Physical Activity in Older Patients With Cancer: A Six-Month Follow-Up Study. Oncology Nursing Forum v. 36, n. 2, p. 194-202, 1 mar. 2009. Disponível em: <http://www.ncbi.nlm.nih.gov/pubmed/19273408>

REIS, Andréa Dias et al. Effect of exercise on pain and functional capacity in breast cancer patients. Health and Quality of Life Outcomes v. 16, n. 1 , p. 58,6 dez. 2018. Disponível em: <http://www.ncbi.nlm.nih.gov/pubmed/29625622>

UNIVERSIDADE FEDERAL DA PARAÍBA., Giane Dantas De et al. The Life Style Influence on the Quality of Life of Women with Breast Cancer. Rev. bras. ciênc. saúde v. 14, n. 4 , 2010. Disponível em: <http://bases.bireme.br/cgibin/wxislind.exe/iah/online/?/sisScript=iah/iah.xis \&srC=google\&base $=$ LILACS\&lang $=$ p\&nextAction $=$ Ink\&exprSearch $=601335 \&$ indexSearch $=\mid \mathrm{D}>$. .

SABISTON CM, BRUNET J. Reviewing the benefits of physical activity during cancer survivorship. Am J Lifestyle Med. 2012;6(2):167-77.

http://ajl.sagepub.com/content/6/2/167.short.

STOUT, Nicole L. et al. A Systematic Review of Exercise Systematic Reviews in the Cancer
Literature (2005-2017). PM\&R, [s.I.], v. 9, p.347384, set. 2017. Wiley. Disponível em: <https://www.ncbi.nlm.nih.gov/pubmed/28942909 $>$.

BUFFART, L.M., KALTER, J., SWEEGERS, M.G., COURNEYA, K.S., et al. Effects and moderators of exercise on quality of life and physical function in patients with cancer: an individual patient data meta-analysis of 34 RCTs. Cancer Treatment Reviews. 2016. Doi: http://dx.doi.org/10.1016/j.ctrv.2016.11.010

IDORN, Manja; STRATEN, Per Thor. Exercise and cancer: from "healthy" to "therapeutic"? Cancer Immunology, Immunotherapy, [s.I.], v. 66, n. 5, p.667-671, 21 mar. 2017. Springer Nature. Disponível em: <https://www.ncbi.nlm.nih.gov/pubmed/28324125 $>$.

JONNA K. van Vulpena, PETRA H.M. PEETERSA, b, MIRANDA J. Velthuisc, ELSKEN van der Walld, ANNE M. May. Effects of physical exercise during adjuvant breast cancer treatment on physical and psychosocial dimensions of cancer-related fatigue: A metaanalysis. Maturitas. 2016 Mar; 85:104-11. doi: 10.1016/j.maturitas.2015.12.007.

HOLMES MD, CHEN WY, FESKANICH D, KROENKE CH, COLDITZ G. After breast cancer diagnosis. J Am Med Assoc. 2014;293(20):247986.

URBSCHEIT N, BROWN K. The association between physical activity and breast cancer recurrence and survival. Curr Nutr Rep. 2014; 3:16-21.

NELSON SH, MARINAC CR, PATTERSON RE, et al. Impact of very low physical activity, BMI, and comorbidities on mortality among breast cancer survivors. Breast Cancer Res Treat. 2016;155(3):551-7.

SPECK RM ${ }^{1}$, COURNEYA KS, MÂSSE LC, DUVAL S, SCHMITZ KH. An update of controlled physical activity trials in cancer survivors: a systematic review and metaanalysis. $J$ Cancer Surviv. 2010 Jun;4(2):87-100. doi: 10.1007/s11764-009-0110-5.

SHIM, Yoo Jin et al. Exercise during adjuvant treatment for colorectal cancer: treatment completion, treatment-related toxicities, body composition, and serum level of 


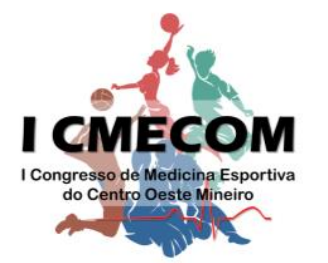

\begin{abstract}
ANAIS DO I CONGRESSO DE MEDICINA ESPORTIVA DO CENTRO-OESTE MINEIRO
\end{abstract}

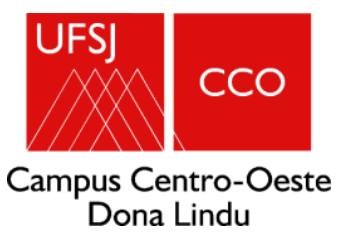
adipokines. Cancer $\quad$ Management and
Research, [s.l.], v. 11, p.5403-5412, jun. 2019. Dove Medical Press Ltd. Disponível em: $<$ https://www.ncbi.nlm.nih.gov/pubmed/31354348 $>$.

of life among colorectal cancer survivors. Journal of Clinica Oncology, v. 26, n. 27, p. 4480-4487, 2008. Disponível em: <https://ascopubs.org/doi/full/10.1200/JCO.2007. 15.7917>

LYNCH, Brigid M. Et al. Prospective relationships of physical activity with quality 


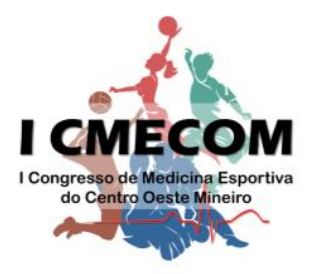

\title{
TRATAMENTO CIRÚRGICO DA DESINSERÇÃO COMPLETA DO TENDÃO DO PEITORAL MAIOR UTILIZANDO ENXERTO DE FÁSCIA LATA - RELATO DE CASO
}

\author{
Maria Laura Domingues, Pedro Henrique Ferreira, Vanessa Takata, Lucas Moreira \\ Brito, William Alves Bueno, Carlos Guilherme Alvim Costa Leite, João Pedro Costa \\ Marques \\ Contato: marialauradomingues@hotmail.com
}

Introdução: A rotura do peitoral maior é mais frequente em jovens praticantes de exercícios com peso. O uso de anabolizantes tem sido associado ao maior risco de rotura de tendões. Embora o risco esteja aumentado para os usuários crônicos, a literatura ainda não descarta a relação entre o uso esporádico e o risco aumentado de lesão. O presente trabalho é um relato de caso de paciente praticante de musculação e uso prévio de anabolizante com rotura do tendão do peitoral maior. Objetivos: 0 objetivo do estudo é mostrar uma possível relação entre a utilização de anabolizante e a rotura de tendão, além de evidenciar o sucesso da técnica cirúrgica utilizada. Materiais e métodos: Foram utilizados dados do prontuário do paciente e pesquisas na base de dados PubMed. Relato de caso: Homem, 30 anos, masculino, com desinserção total do peitoral maior durante realização de supino reto. Paciente previamente hígido com história de uso de esteróide anabolizante aos 18 anos. Realizada ressonância magnética que evidenciou desinserção umeral completa do tendão do peitoral maior. Foi submetido à cirurgia por via aberta com 4 semanas de lesão. Utilizado acesso delto-peitoral e o tendão roto encontrava-se em processo de cicatrização junto à cabeça longa do bíceps logo abaixo do ligamento transverso, com qualidade ruim. Devido ao uso prévio de anabolizante e tendão de qualidade comprometida, foi optado por retirar enxerto de fáscia lata em face lateral da coxa, retirado seguimento de fáscia lata medindo cerca de $15 \mathrm{~cm}$ de comprimento por 5 de largura. $O$ enxerto foi preparado, dobrado sobre si próprio no sentido longitudinal, o tendão roto foi envolvido pelo enxerto até a junção miotendínea do peitotal maior, realizadas suturas enxerto-tendão com fio não absorvível, posicionadas 2 âncoras metálicas $5.0 \mathrm{~mm}$ carregadas com 2 fios cada no sentido longitudinal do footprint no úmero, realizadas suturas do tipo kracow no tendão reconstruído, feita reinserção e sutura da pele. No pós-operatório, paciente fez uso de tipóia americana durante 6 semanas. Resultado e discussão: Após 2 semanas de pós-operatório, foi realizada retirada de pontos, evidenciada melhora da deformidade estética e orientado a realizar exercícios pendulares e auto-passivos, quatro vezes por dia, evitando abdução acima de 45․ Com 6 semanas de cirurgia, foi retirada tipóia e prescrito início de reabilitação. Após 6 meses de cirurgia, foi observada patência da função do tendão e paciente assintomático, sendo liberado para realização de atividade física com os membros superiores. Conclusão: Diante do exposto, o enxerto de fáscia lata é uma boa alternativa em casos de tendões degenerados e a utilização de anabolizante, mesmo que esporádica, parece ter interferido na qualidade do tendão do paciente visto à baixa idade do mesmo e à ausência de comorbidades que poderiam afetar a qualidade do tendão. Contudo, mais estudos são necessários para verificar essas relações. 
Palavras-chave: "pectoralis major"; "rupture"; "anabolic steroid"; "resistance training"

\section{Referências Bibliográficas:}

1. Kanayama G, DeLuca J, Meehan WP 3rd, et al. Ruptured Tendons in Anabolic-Androgenic Steroid Users: A Cross-Sectional Cohort Study. Am J Sports Med. 2015;43(11):2638-2644. doi:10.1177/0363546515602010

2. Bak, K., Cameron, E. \&amp; Henderson, I. Knee Surgery (2000) 8: 113. https://doi.org/10.1007/s001670050197

3. Cordasco, Frank A. et al. Pectoralis major tendon tears: functional outcomes and return to sport in a consecutive series of 40 athletes Journal of Shoulder and Elbow Surgery. 2017, Volume 26, Issue 3, 458 - 463.
4. Jones, I. A., Togashi, R., Hatch, G. F., Weber, A. E. and Vangsness, C. T. (2018), Anabolic steroids and tendons: A review of their mechanical, structural, and biologic effects. J. Orthop. Res., 36: 2830- 2841. doi:10.1002/jor.24116

5. Pectoralis major ruptures: a review of current management Butt, Usman et al. Journal of Shoulder and Elbow Surgery. 2015, Volume 24, Issue 4, $655-662$.

6. A systematic review and comprehensive classification of pectoralis major tears ElMaraghy, Amr W. Et al. Journal of Shoulder and Elbow Surgery. 2012, Volume 21, Issue 3, 412 - 422. 


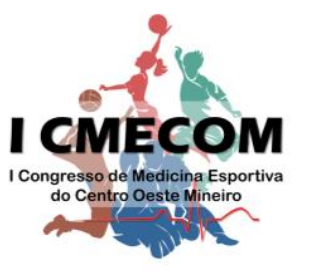

\section{A PRÁTICA DE EXERCícIOS FÍSICOS EM GESTANTES DE ALTO RISCO}

Ingrid Morselli Santos, Carlos Guilherme Alvim Costa Leite, Renato Martins Antunes, Raphael Souza Fernandes

Contato: raphaelfernandes2008@hotmail.com

Introdução: O exercício físico é definido como uma atividade física estruturada, metódica e repetitiva que visa manter ou otimizar o condicionamento. Desde a década de 1950, os estudos médicos associaram o exercício a inúmeros resultados benéficos e, nos últimos anos, tem havido uma maior preocupação com a saúde física e a prática de exercícios entre a população feminina, incluindo mulheres grávidas. Essa prática, antes desencorajada para gestantes, hoje tem recomendações bem estabelecidas pelo Colégio Americano de Obstetras e Ginecologistas (ACOG). Objetivos: Avaliar os efeitos do exercício físico na saúde materno-fetal em gestações de alto risco. Metodologia: Foi realizada uma revisão bibliográfica utilizando a base de dados PubMed, e SciELO, entre 2009 e 2019, a partir dos descritores: exercício, gestação, alto risco. Resultados: $\mathrm{Na}$ análise da literatura, gestantes expostas a diversas intervenções de exercícios mostraram que a prática foi bem-sucedida na prevenção e controle do Diabetes Mellitus Gestacional (DMG). A melhora do controle dos níveis glicêmicos associados à atividade física logo foram reconhecidos por reduzirem a resistência periférica à insulina. Os estudos que não obtiveram desfechos favoráveis tiveram como limitações abandono e falta de comprometimento com a prática. Os resultados foram divergentes quanto à prevenção de distúrbios hipertensivos gestacionais e desfechos fetais favoráveis. Foi evidente que as atividades físicas são capazes de reduzir a pressão arterial, mas sem resultados expressivos na prevenção de síndromes hipertensivas da gestação. Entretanto, estudos que implementaram yoga mostraram-se eficazes na prevenção de tais síndromes, sugerindo o importante papel dos antioxidantes, que tem maior expressão em pacientes expostos a protocolos de alongamento. Além disso, exercícios de alongamento, como o yoga, têm importância na redução da lombalgia durante a gestação. As gestantes com excesso de peso que se exercitavam ganharam, de um modo geral, menos peso durante toda a gestação. Em relação aos desfechos fetais, as crianças nascidas de mães que se exercitaram tiveram melhores escores de Apgar, porém sem diferença no peso ao nascer. Não houve aumento no número de partos prematuros, abortos espontâneos ou outros eventos adversos. Conclusão: Estimular a adoção de estilo de vida saudável deve ser parte da orientação médica e sistematizada para todas as mulheres em qualquer fase da vida. Os riscos dos exercícios físicos durante a gestação são mínimos quando supervisionados e atestados pelos médicos. A atividade física é eficaz na prevenção e controle do DMG em gestantes de alto risco. Atividades de alongamento e ioga parecem ser mais eficazes na prevenção de síndromes hipertensivas. 

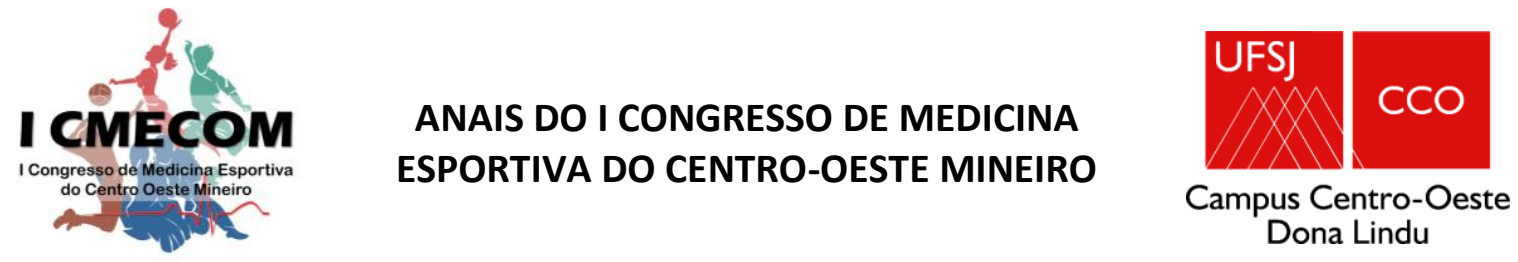

Referências Bibliográficas:

Gasparin V, Albrecht C, Favero D, Gregolin K, Pitilin É, de-Resende-e-Silva D. Physical activity in pregnant women as prevention of gestational hypertensive syndrome. Journal of Nursing UFPE. 2018 Apr 4; 12(4): 1017 - 1026.

Martins ABT, Santos ZMSA, Silva Junior GB, Liberato Filho GFP, Saintrain MVL, Caldas JMP, Andrade IRC, Palácio JSF. Adhesion of the

pregnant to the physical exercise for the prevention and / or control of the risk of hypertensive syndrome. 2016 Dec; 29(Supl): 2535.

Nascimento SL, Godoy AC, Surita FG, Silva JLP. Recomendações para a prática de exercício físico na gravidez: uma revisão crítica da literatura. Rev Bras Ginecol Obstet. 2014; 36(9):423-31. 


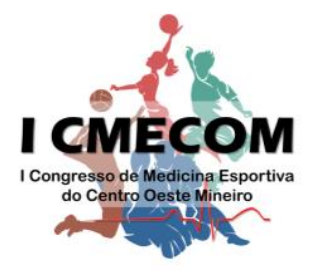

\section{LESÕES MÚSCULO-ESQUELÉTICAS NO OMBRO DE ATLETAS: UMA REVISÃO BIBLIOGRÁFICA}

Luiza Gabriela Noronha Santiago, Ingrid Morselli Santos, Priscila Cristian do Amaral, Naiara Patrícia Fagundes Bonardi, Anna Karolyna Rodrigues Cunha, Pedro Henrique Santos Ribeiro, Carlos Guilherme Alvim Costa Leite

Contato: lukansantiago@gmail.com

Introdução: O ombro é sede frequente de lesões nos esportes competitivos com a incidência de até $15 \%$ de todas as lesões atléticas. Nos esportes de arremesso as lesões nos membros superiores giram em torno de $75 \%$ do total e a articulação do ombro é a região mais afetada. Objetivos: Avaliar os esportes envolvidos, mecanismo de lesão e retorno ao esporte de atletas após lesão do ombro. Metodologia: Foi realizado uma revisão bibliográfica utilizando a base de dados Scielo e PubMed entre os anos 2009 e 2019. Foram selecionados 4 artigos, utilizando os descritores: lesão muscular; ombro; epidemiologia. Resultados: Durante o arremesso o centro de massa de um corpo ou objeto externo é propelido para fora, por isso, predispõe lesões das estruturas do ombro. A energia envolvida nesses movimentos ultrapassa o limite fisiológico do ombro. Os mecanismos de lesões no ombro do atleta ocorrem por meio traumático e atraumático. Os traumas ocorrem principalmente em esportes como luta que priorizam o contato físico. Já em esportes de não-contato, como vôlei e natação, - atleta realiza movimentos repetitivos que podem ser responsáveis por grande número de lesões atraumáticas. De acordo com a revisão, o mecanismo de lesão por não-contato (atraumático) foi o mais frequente, logo, os esportes que mais afetaram foram vôlei, natação e artes marciais. O principal sintoma manifestado pelos atletas é a dor. O ombro doloroso afeta tanto o atleta de alto nível quanto o amador. Com relação aos tipos das lesões, as luxações glenoumeral e acromioclavicular e as tendinites são as mais frequentes. O uso de métodos de imagem (ultrassonografia, radiografia e ressonância magnética) para auxílio no diagnóstico é importante para o ombro do atleta. O retorno ao esporte depende de fatores individuais, mas ocorre, em média, após sete semanas da lesão, podendo levar até cinco meses em casos de luxações recorrentes. Conclusão: As lesões esportivas do membro superior são corriqueiras nas práticas esportivas. Lesões atraumáticas afetam com maior frequência esportes de não-contato e atletas arremessadores. A dor é o principal sintoma referido e afeta tanto o atleta de alto rendimento quanto o amador. A ultrassonografia é o exame mais empregado para diagnóstico. É fundamental uma preparação na área médica e de educadores físicos para que mecanismos de prevenção de lesões sejam implementados.

Referências Bibliográficas

ASTUR, Diego Costa et al. Lesão muscular: perspectivas e tendências atuais no Brasil. Rev. bras. Ortop., São Paulo, v. 49, n. 6, p. 573-580, Dec. 2014.
Raymundo, José Luiz Pozo et al. Perfil das lesões e evolução da capacidade física em atletas profissionais de futebol durante uma temporada. Ver Bras Ortop. 2005;40(6):341-48. 

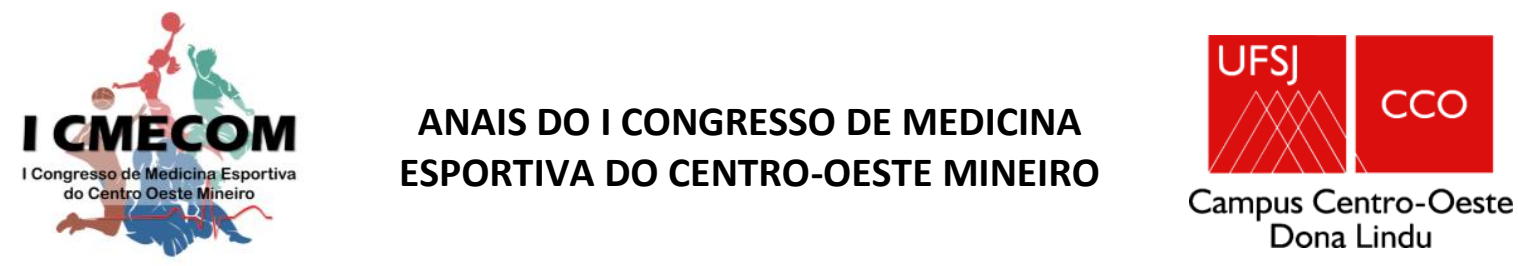

SILVA, Rogerio Teixeira da. Lesões do membro superior no esporte. Rev. bras. Ortop., São Paulo, v. 45, n. 2, p. 122-131, 2010.

VIEIRA, Fabio Antonio et al. Lesão do manguito rotador: tratamento e reabilitação. Perspectivas e tendências atuais. Rev. bras. Ortop., São Paulo, v. 50, n. 6 , p. 647-651, Dec. 201 


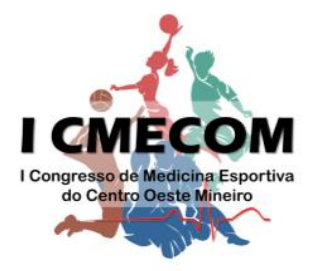

\section{PRESENÇA E SEVERIDADE DE INSÔNIA EM PRATICANTES DE EXERCÍCIOS FÍSICOS E INDIVÍDUOS SEDENTÁRIOS: UM COMPARATIVO}

Jacqueline Alves, Cintia Aparecida Santos, Gabriela Ribeiro de Oliveira, Gabriela Viana Santos, Gleison Silva Morais, Layra Fernanda Martins, Newton Santos de Faria Junior, Lucas Rios Drummond, José Vitor Vieira Salgado, Julia Vieira Salgado Silva Contato: jacqealv@hotmail.com

INTRODUÇÃO: O sono normal varia ao longo do desenvolvimento humano quanto à duração, distribuição de estágios e ritmo. Com o avançar da idade, ocorrem perdas na duração, manutenção e qualidade do sono. Dentre os distúrbios do sono, a insônia é a mais prevalente, sendo pouco diagnosticada e nem sempre adequadamente tratada. Sabe-se que prática de atividades físicas regulares pode contribuir significativamente para a manutenção do bem-estar e da qualidade de vida da população em geral, proporcionando inúmeros benefícios, como a qualidade do sono. OBJETIVO: Comparar a presença e severidade de insônia em indivíduos praticantes de exercícios físicos e indivíduos sedentários. MÉTODOS: O presente estudo foi do tipo observacional transversal, realizado com amostra consecutiva e de conveniência. Realizado pelos alunos do curso de Fisioterapia e Educação Física, e o mesmo foi aprovado pelo Comitê de Ética em Pesquisa com Seres Humanos da universidade, sob número de protocolo 85018318.9.0000.5115. Todos os pacientes foram avaliados clinicamente e responderam ao Índice de Gravidade de Insônia para avaliar presença e gravidade de insônia. RESULTADOS: Participaram do estudo 294 indivíduos, sendo 255 praticantes de exercício físico e 39 indivíduos sedentários, com média de idade de 23,20 anos $( \pm 10,1)$ anos e IMC de $23,7 \mathrm{~kg} / \mathrm{m} 2( \pm 3,2)$. Sendo, $53,6 \%$ dos pacientes do sexo feminino. O estudo aponta que dos indivíduos sedentários, 53,83\% apresentaram insônia, sendo 85,71\% leve, 9,52\% moderada e 4,77\% severa. No caso dos praticantes de exercício físico, 35,69\% apresentaram insônia, sendo 74,73\% leve, $20,88 \%$ moderada e $4,40 \%$ severa. CONSIDERAÇÕES FINAIS: Verificou-se a presença de insônia em ambos os grupos de indivíduos, entretanto, percebe-se a incidência maior que $50 \%$ nos indivíduos sedentários. No caso dos praticantes de exercícios físicos, mais de 60\% não apresentaram insônia, corroborando com a literatura a respeito dos benefícios da atividade física regular.

\section{REFERÊNCIAS BIBLIOGRÁFICAS}

REID, Kathryn J. et al. Aerobic exercise improves self-reported sleep and quality of life in older adults with insomnia. Sleep Medicine, [s.I.], v. 11, n. 9, p.934-940, out. 2010. Elsevier BV.

LOWE, Hayley et al. Does exercise improve sleep for adults with insomnia? A systematic review with quality appraisal. Clinical Psychology Review, [s.I.], v. 68, p.1-12, mar. 2019. Elsevier BV.
DA SILVA, Carlos Alberto; DE LIMA, Walter Celso. EXERCÍCIO FÍSICO NA MELHORA DA QUALIDADE DE VIDA DO INDIVÍDUO COM INSÔNIA. Movimento (ESEFID/UFRGS), Porto Alegre, v. 7, n. 14, p. 49-56, nov. 2007.

DEMENT, W.C. A personal history of sleep disorders medicine. J. Clin. Neurophysiol., v.7, n.1, p. 17-47, 1990. 


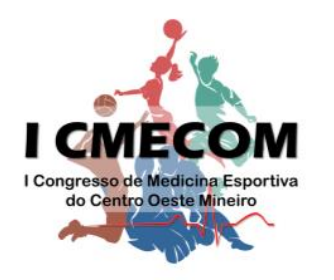

\title{
AS VARIÁVEIS DO PROGRAMA DE TREINAMENTO NA MUSCULAÇÃO PARA MELHORA DA PERFORMANCE - UMA REVISÃO BIBLIOGRÁFICA
}

\author{
Pedro Henrique Santos Ribeiro, Caique José Duarte Avelar, Ingrid Morselli Santos, \\ Priscila Cristian do Amaral, Rafael Rezende Ferreira da Costa, Amanda Isadora \\ Santos Ribeiro \\ Contato: p.pedroribeiro95@gmail.com
}

Introdução: A musculação é entendida como meio de treinamento que oferece alguma carga mecânica em oposição ao movimento dos segmentos corporais ${ }^{1}$. Sua prática e a melhora da performance, sendo essa o aumento de força e hipertrofia muscular, é dependente de variáveis estruturais- elementos primários para elaboração e análise de um programa de treinamento. Objetivo: Realizar uma revisão da literatura para discorrer sobre o conceito e aplicabilidade na prática das principais variáveis que influenciam no treinamento e melhora da performance em musculação. Metodologia: Esta revisão investigou a literatura publicada no PubMed e Medline nos últimos 10 anos. Os descritores utilizados foram: musculação, treino resistido, programa de treinamento e hipertrofia. Resultados: A literatura vem considerando uma série de variáveis para melhora da performance em musculação ${ }^{1}$. Ação muscular é a variável que trata das formas de contração muscular- concêntrica, excêntrica e isométrica. Os trabalhos analisados mostraram que é recomendável a inclusão de todas elas para todos praticantes- iniciantes, intermediários e avançados. $O$ volume de treino corresponde ao trabalho total realizado em um tempo determinado e está intimamente relacionado com o peso, número de repetições e séries ${ }^{2,3}$. O peso é a variável definida como resistência externa e pode ser dimensionado através do percentual de resistência máxima $(\mathrm{RM})$ - quantidade de peso levantada em um esforço máximo ${ }^{4}$. É recomendável que iniciantes e intermediários usem pesos moderados $(70 \%$ a $85 \%$ de $1 \mathrm{RM})$, realizem 8 a 12 repetições por série e 1 a 3 séries por exercícios com período de descanso de 1 a 2 minutos entre elas; enquanto praticantes avançados usem pesos equivalentes a $70 \%$ a $100 \%$ de $1 \mathrm{RM}$, realizem 1 a 12 repetições por série e 3 a 6 séries por exercício com período de descanso de 1 a 3 minutos dependendo da intensidade do exercício feito. Exercícios mono e multiarticulares mostraram gerar hipertrofia muscular, devendo ser usados em todos praticantes. Quanto à ordem, tem sido visto que exercícios que demandam mais esforço devem preferivelmente ser realizados no início de uma sessão de treino. A velocidade de repetição mostrou-se variável de acordo com o nível do praticante e do exercício feito. É recomendável frequência de treinos de 2 a 3 dias por semana (d/s) para iniciantes, $4 \mathrm{~d} / \mathrm{s}$ para intermediários e $6 \mathrm{~d} / \mathrm{s}$ para avançados². Conclusão: Variáveis estruturais têm grande relevância para o entendimento adequado do treinamento em musculação. A modificação em uma variável resulta frequentemente em mudanças significativas em outras, o que impossibilita a prescrição de treinamento meramente por fórmulas préestabelecidas e demonstra o nível de complexidade em conhecê-las como ferramentas para melhora da performance. 


\section{Referências Bibliográficas:}

Lima, F. V., \& Chagas, M. H. (2009). Musculação: Variáveis estruturais. Belo Horizonte: Casa da Educação Física.

Ratamess NA, Alvar BA, Evetoch TK, Housh TJ, Kimbler WB, Kraemer WJ, Triplett NT. Position Stand: progression models in resistance training for healthy adults. American College of Sports Medicine. 2009, 41(3):687-708.

Garber CE, Blissmer B, Deschenes MR, Franklin BA, Lamonte MJ, Lee I, Nieman DC, Swain DP.
Quantity and Quality of Exercise for Developing and Maintaining Cardiorespiratory, Musculoskeletal, and Neuromotor Fitness in Apparently Healthy Adults: Guidance for Prescribing Exercise. Medicine \& Science in Sports \& Exercise. 2011, 43: 1334-1359.

Ferreira JU, Gonçalves PV, Franchini E. Predição da carga máxima a partir do número máximo de repetições com cargas submáximas para mulheres. Rev. bras. cineantropom. Desempenho hum.2011 Oct. 


\title{
EXERCÍCIO FÍSICO E AS POSSÍVEIS DOENÇAS ALÉRGICAS ASSOCIADAS À SUA PRÁTICA
}

\author{
Letícia Thaís de Oliveira Alves, Luiza Noronha Gabriela Santiago, Naiara Patrícia \\ Fagundes Bonardi, Priscila Cristian do Amaral \\ Contato: leticiaathaiss1704@gmail.com
}

Introdução: O conhecimento acerca dos benefícios do exercício físico na saúde é constantemente demonstrado na literatura, sendo parte de uma estratégia do Ministério da Saúde para promoção do exercício físico na população. Contudo, a associação entre doenças alérgicas e o exercício físico é pouco difundida na sociedade. Os indivíduos alérgicos são suscetíveis a terem sintomas induzidos pelo exercício durante a prática desportiva, constituindo assim um prejuízo quanto ao seu desempenho esportivo. Objetivo: Avaliar quais as possíveis doenças alérgicas relacionadas à prática de exercícios físicos e a importância de reconhecer tais patologias tanto pelo indivíduo alérgico, quanto pelos profissionais de saúde. Metodologia: Fez-se uma revisão bibliográfica nas bases de dados SCIELO, LILACS e MEDLINE, utilizando-se os descritores "alergia" e "exercício físico", sendo encontrados 17 artigos e selecionados 5 artigos. Resultados: As patologias encontradas foram asma/broncoconstrição induzida pelo exercício (AIE/BIE), rinite associada ao exercício, anafilaxia induzida pelo exercício (AnIE) e urticária induzida pelo exercício. A AIE/BIE ocorre por ser o esforço físico um dos estímulos que podem produzir episódios de obstrução das vias aéreas em pessoas com asma, sendo a atividade física a segunda causa de broncoconstrição. Muitos atletas possuem rinite associada ao exercício, desenvolvendo rinorreia, congestão e espirros durante exercícios intensos, como corrida ou desportos de inverno, afetando indiretamente o seu rendimento. Na AnIE pode ocorrer fadiga, rubor, prurido difuso, urticária, angioedema, broncoespasmo, dispneia, choque cardiocirculatório e edema laríngeo e pode estar relacionada a alimentos (como trigo e frutos do mar), com ou sem sensibilização IgE-específica, e pode haver ainda fármaco-dependência quanto a sua manifestação (como ácido acetilsalicílico e anti-inflamatórios não esteroidais), sendo essencial que o indivíduo com AnIE saiba utilizar o kit de adrenalina auto injetável para ter a regressão do quadro. Por fim, a urticária induzida pelo exercício caracteriza-se por pápulas que se instalam rapidamente e são seguidas de prurido ou sensação de calor ou ardor e podem associar-se a angioedema, salivação, dores abdominais, vômitos, diarreias, aumento da atividade brônquica e síncope. Conclusão: Diante disso, é importante que a prática física seja supervisionada quando se trata de pacientes alérgicos à prática de exercício físico. Além disso, é de suma relevância conscientizar os diversos profissionais de saúde sobre a existência, tratamento e o manejo dessas patologias. Os educadores físicos, essencialmente, devem ser treinados sobre como agir diante da referida alergia, pois costumam ser os primeiros a presenciar os relatos de pacientes acometidos. 


\section{Referências Bibliográficas}

Brasil. Ministério da Saúde. Secretaria de Vigilância em Saúde. Política nacional de promoção da saúde / Ministério da Saúde, Secretaria de Atenção à Saúde. Brasília: Ministério da Saúde; 2006.

Couto M, Silva D, Marques J, Paiva M, Jacinto T, Câmara R. Doenças alérgicas na prática desportiva. Rev Port. Imunoalergologia 2017; 25 (4): 259-275.

Mario Geller, MD, MACP, FAAAAI, FACAAI. Anafilaxia induzida por exercício: atualização. Braz J Allergy Immunol 2015; 3(2): 40-6.
Caiado J, Ferreira MB, Pedro E, Barbosa MP. Anafilaxia induzida por exercício dependente de alimentos - Caso clínico. Rev Portlmunoalergologia 2007; 15 (2): 179-187.

Maia CS, Lira PRB, Maciel GES, Nascimento FCP, Tenorio FCAM. Anafilaxia induzida por exercícios físicos, um transtorno pouco conhecido entre os diversos profissionais de saúde. Anais do 2. Congresso Brasileiro de Ciencias de Saúde; 2017 jun 14-16; Campina Grande, Paraíba, Brasil. Campina Grande: Realize; 2017. 


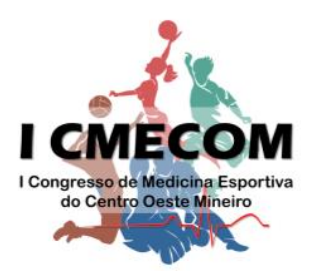

ANAIS DO I CONGRESSO DE MEDICINA ESPORTIVA DO CENTRO-OESTE MINEIRO

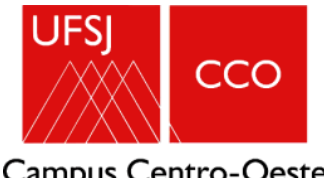

Campus Centro-Oeste

Dona Lindu

\section{ASPECTOS GERAIS DA ABORDAGEM DA MORTE SÚBITA EM ATLETAS}

Luiza Gabriela Noronha Santiago, Letícia Thais de Oliveira Alves, Viviane Cunha Silva, Ingrid Morselli Santos, Priscila Cristian do Amaral Contato: lukansantiago@gmail.com

Introdução: Morte súbita (MS) em atletas gera intensa perturbação social quando divulgada pela mídia. Isso ocorre porque a morte de desportistas de maneira inesperada é contraproducente a ideação de saúde e vitalidade condicionada a esse grupo. ${ }^{1-5}$ Atletas têm cerca de duas vezes mais risco de ocorrência de MS em relação ao grupo controle, o que sustenta a necessidade de rastreamento desses indivíduos. 1,3-4 Objetivo: Discutir a literatura científica no que se refere à abordagem da MS em atletas na última década. Metodologia: Foi realizada uma revisão bibliográfica com sete artigos datados entre 2010 e 2019. Utilizou-se os descritores morte súbita, morte súbita cardíaca e atletas nas bases de dados LILACS, MEDLINE e SCIELO. Resultados: A MS em atletas tem, usualmente, etiologia cardiovascular, sendo o exercício físico intenso o principal fator desencadeante para ocorrência do fenômeno. 1,3-5. Outros fatores tais como o uso de drogas estimulantes do sistema nervoso central, de esteroides anabolizantes e do hormônio do crescimento também são relevantes. ${ }^{1,2} \mathrm{~A}$ fim de prevenir eventos de MS, entidades de saúde recomendam que atletas se submetam a exames pré-participação (EPP) para detecção de fatores de risco. ${ }^{1-7}$. Este deve ser reproduzido anualmente em atletas profissionais e no mínimo a cada dois anos para amadores. ${ }^{5}$ No Brasil, a Diretriz sobre a Morte Súbita no Exercício e no Esporte foi baseada nas diretrizes de rastreamento desenvolvidas pela European Society of Cardiology (ESC). 1,3 A ESC recomenda que o EPP contemple anamnese e exame físico com enfoque no aparelho cardiovascular e eletrocardiograma (ECG) de repouso de 12 derivações. Em contrapartida, entidades como American College of Cardiology (ACC) e American College of Sports Medicine (ACSM) desqualificam a obrigatoriedade do ECG à medida que esse exame aumenta o número de anormalidades falso-positivas, o que gera ônus financeiro devido a uma propedêutica adicional desnecessária, além de potencializar danos psicológicos aos indivíduos expostos ao processo. ${ }^{1,4-6}$. Somado a isso se tem o despreparo de profissionais médicos para identificar um quadro clínico potencial para MS em um contexto em que mais da metade de atletas falecidos por MS cardíaca apresentaram pelo menos um sintoma subestimado pelo examinador. A fim de aumentar o valor preditivo da avaliação clínica, o ecocardiograma pode ser utilizado na prática de triagem. Contudo, trata-se de um método examinador-dependente, havendo carência de profissionais hábeis para tal finalidade. ${ }^{5-6}$ Conclusão: Atualmente, anamnese e exame físico ainda são as principais ferramentas de triagem de atletas, entretanto, apresentam baixa sensibilidade quando usados para screening e, por isso, devem ser associados a exames como o ECG e/ou ecocardiograma. Para efetividade destes faz-se necessário a capacitação dos profissionais médicos para a sua interpretação adequada. 


\section{Referências Bibliográficas}

1 Helal L, Ferrari F, Stein R. Morte Súbita no Atleta Jovem Brasileiro: Não Será Hora de Criarmos um Registro Genuinamente Nacional? Arq. Bras Cardial. 2018; 111(6): 856-859.

2 Ghorayeb N, Colombo CSSS, Francisco RC, Garcia TG. Sudden Cardiac Death in Sports: Not a Fatality. Int. J Cardiovasc Sc. 2019; 32(1): 8486.

3 Garcia JH, Costa PFM. Morte súbita em atletas: protocolos e rotinas adotados por clubes de futebol profissional em São Paulo. Rev Bras Med Esporte. 2011; 17(3): 161-165.

4 Asif IM, Harmon KG. Incidence and Etiology of Sudden Cardiac Death: New Updates for Athletic Departments. Sports Health. 2017; 9(3): 268-279.
5 Diaz R. F et al. Rol de la evaluación preparticipativa en adolescentes, en el diagnóstico de enfermedades cardiovasculares y prevención de muerte súbita. Rev Med Chile. 2010. 138(2); 223-232.

6 Peidro R, Froelicher V, Stein R. Triagem préparticipação do atleta jovem: é essa a hora para um consenso? Arq Bras Cardiol. 2011; 96(3): 5052.

7 Katch RK, Scarneo SE, Adams WM, Armstrong LE, Belval LN, Stamm JM Casa DJ. Top 10 Research Questions Related to Preventing Sudden Death in Sport and Physical Activity. Res Q Exerc Sport. 2017; 88(3): 251-268. 


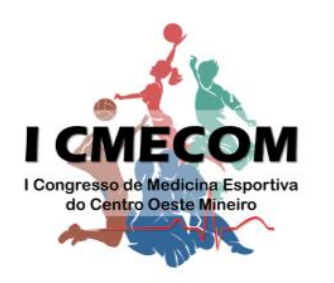

\section{AS VANTAGENS DA INCLUSÃO DO ESPORTE NA VIDA DA POPULAÇÃO IDOSA}

Carolina Aparecida Alves Bueno, Gesana de Sousa Afonso, Cheila Alves de Oliveira, Maicon Júnio da Silva Alves Oliveira

Contato: enfermeiracarolinabueno@gmail.com

Introdução: Envelhecer é um processo que ocorre naturalmente e é caracterizado por uma série de alterações, principalmente a partir dos 60 anos. O indivíduo idoso passa por um declínio funcional devido a diminuição de sua reserva fisiológica, sendo aumentado o risco de quedas, fraturas e dependência funcional. A prática regular do exercício físico é um fator importante, podendo ser realizada através de esportes, promovendo benefícios físicos, psicológicos e sociais para essa faixa etária, auxiliando na redução de doenças, na reabilitação da saúde do idoso, facilitando a manutenção de bons níveis de independência e autonomia para as atividades diárias, contribuindo na manutenção da capacidade funcional dessa população. Objetivos: Promover e avaliar as vantagens do condicionamento físico da população idosa mediante a prática de atividades físicas, resultando na melhora da funcionalidade e qualidade de vida. Metodologia: O proposto trabalho compreende em uma Revisão de Literatura. O levantamento bibliográfico foi realizado por meio de uma busca nas bases de dados BDENF, LILACS, IBECS do sítio da Biblioteca Virtual de Saúde - BVS e Periódicos CAPES, dos últimos cinco anos e no idioma em português. Foram identificados 15 estudos, exclui-se onze referencias após leitura do resumo. A amostra finalizou-se com quatro artigos. Resultados: A limitação ou a não realização de atividades físicas, desenvolve um quadro de incapacidade funcional do idoso, podendo causar o aumento da incidência de doenças cardiovasculares e a diminuição da capacidade funcional em consequência do declínio de alguns componentes de capacidade física, como resistência aeróbica, coordenação e força muscular. O fortalecimento da musculatura e da capacidade nos movimentos contribuem com a autoestima e autoimagem gerando maior autonomia, independência e ampliação nas relações sociais. Os benefícios da atividade física também contribuem para a diminuição dos custos da sociedade envelhecida, mediante a prevenção de morbidades e da mortalidade entre os idosos. Conclusão: A prática de exercícios físicos deve ser incentivada por órgãos governamentais como forma de manutenção da capacidade funcional, contribuindo para melhor qualidade de vida dessa população, auxiliando na redução dos gastos públicos em decorrência de doenças que surgem com o envelhecimento. Deve-se priorizar o desenvolvimento da capacidade aeróbia, flexibilidade, equilíbrio, resistência e força muscular, de modo a proporcionar uma série de benefícios específicos a saúde biopsicossocial do idoso. É necessário compreender os fatores associados as práticas de atividades físicas, para a elaboração de estratégias específicas de intervenção promovendo a adesão da população idosa a essas atividades. Destaca-se se ainda, como uma limitação do estudo, o número reduzido das pesquisas relacionadas ao tema proposto. 


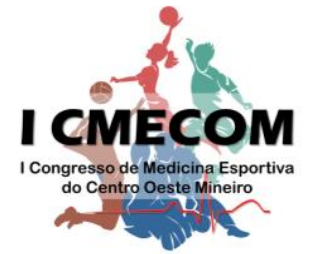

\section{UFSJ \\ Campus Centro-Oeste Dona Lindu}

\section{Referências Bibliográficas:}

Romano TA, Ferreira EF, Gomes AKV, Oliveira RAR. Prática de exercicio físico na meia e Terceira idade: Um estudo comparative dos níveis de capacidade functional em praticantes de ginastica localizada e não praticantes. Revista Brasileira de Prescrição e Fisiologia do Exercício. Maio/Jun 2018; 12(74): 370-376.

Bazello B, Portella FC, Antunes GPP, Gatti AL. Prática esportiva do idoso: Autoimagem, autoestima e qualidade de vida. Boletim de Psicologia. Set 2016; 67 (145): 187-197.

Maciel MG. Atividade física e functional do idoso. Out/Dez 2010; 16 (4): 1024-1032.

Salmela LFT, Santos LD, Goulart F, Cassiano LG, Hirochi TL. Efeitos de atividade física e terapêuticas em adultos maduros e idosos. Fisioterapia Brasil. Março/ Abril 2001; 2 (2): 99106. 


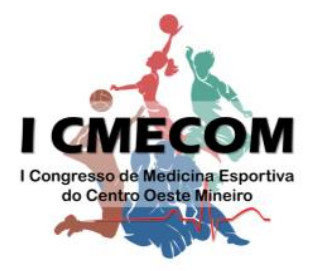

\section{A EDUCAÇÃO FÍSICA ESCOLAR PARA A CRIANÇA COM SÍNDROME DE DOWN: A NECESSIDADE DA PREVẺNÇÃO DE LESÕES DEVIDO À INSTABILIDADE ATLANTOAXIAL}

Pedro Henrique Santos Ribeiro, Ingrid Morselli Santos, João Vitor Liboni Guimarães Rios, Priscila Cristian do Amaral

Contato: p.pedroribeiro95@gmail.com

Introdução: A prática de atividade física é estimulada na busca da qualidade de vida para as crianças com Síndrome de Down (SD) pelo seu impacto positivo no desenvolvimento físico, mental e social. Características comuns à SD são as alterações neuromusculares e osteoarticulares - hipotonia muscular, frouxidão ligamentar e hipermobilidade articular - que podem contribuir para a alteração do alinhamento no segmento atlantoaxial. Tal fato aponta a necessidade de um manejo adequado dessas crianças durante a prática da Educação Física Escolar (EFE). Objetivo: Discutir a importância da EFE na vida da criança com SD e os cuidados necessários com essa prática. Metodologia: Foi realizada revisão bibliográfica na base de dados PubMed, entre 2009 e 2019 com as palavras chaves: "Síndrome de Down", "Educação Física", "Instabilidade Articular". Resultados: Um programa de EFE sólido estimula habilidades motoras como consciência corporal, espacial, direcional, temporal e é capaz de promover habilidades de prontidão básicas que são essenciais para crianças com SD. Segundo a Sociedade de Pediatria do Rio de Janeiro, a criança com SD necessita ser assistida desde os primeiros meses de vida pelos pediatras, que precisam orientar os cuidadores quanto às possíveis alterações secundárias à síndrome, como cardiopatias, atraso do desenvolvimento motor e déficit neurológico. Entre adolescentes com SD há a prevalência de obesidade, risco que aumenta conforme a idade, principalmente, em decorrência da falta de atividade física, corroborando com o combate ao sedentarismo desde a infância. A instabilidade atlantoaxial (IAA), que acomete de $10 \%$ a $30 \%$ dos indivíduos com SD, é definida como uma maior mobilidade da primeira vértebra cervical, o atlas, sobre a segunda, o áxis. Exigindo assim, um rotineiro acompanhamento radiográfico da coluna cervical de todas crianças com SD antes de serem liberadas para a prática de esportes. Fazse necessário um programa educacional destinado aos pais e professores de Educação Física quanto aos cuidados com as posições de exagerada flexão, extensão, rotação e giros forçados com a cabeça, de forma a evitar subluxação ou luxação das vértebras e consequente compressão da medula espinhal, quando presente a IAA. Conclusões: Verificou-se que os benefícios proporcionados pela atividade física certamente estão relacionados à qualidade de vida das crianças com $\mathrm{SD}$, já que reduz os riscos de obesidade, que bem caracteriza a vida dessas pessoas, e promove a socialização dos alunos. Ademais, dar ênfase ao diagnóstico de IAA em crianças com SD é de suma importância para adequações na EFE e evita que sua saúde seja colocada em risco. 
Referências Bibliográficas:

ANUNCIACAO, Lívia Maria Ribeiro Leme; COSTA, Maria Piedade Resende da; DENARI, Fátima Elisabeth. Educação Infantil e Práticas Pedagógicas para o Aluno com Síndrome de Down: o Enfoque no Desenvolvimento Motor. Rev. bras. educ. espec., Marília, v. 21, n. 2, p. 229-244, June 2015.

DEFILIPO, Érica Cesário et al. Prevalência de instabilidade atlantoaxial e sua associação com sinais clínicos em crianças com síndrome de down. Rev. bras. crescimento desenvolv. hum., São Paulo, v. 25, n. 2, p. 151-155, 2015.

MATOS, Marcos Almeida. Instabilidade atlantoaxial e hiperfrouxidão ligamentar na síndrome de down. Acta ortop. Bras., São Paulo, v. 13, n. 4, p. 165-167,2005. 


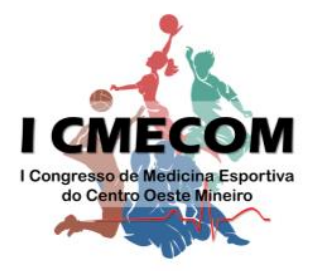

\title{
TREINO FUNCIONAL PARA PORTADORES DE SÍNDROME DE DOWN: UM RELATO DE CASO
}

\author{
Glauco Marciano Pereira, Fabíola Araújo Resende Carvalho \\ Contato: glauco.personal@hotmail.com
}

Atualmente, a Síndrome de Down (SD) é definida como sendo uma anomalia, inserida entre as deficiências mentais, causada por um acidente biológico e integrante do grupo de encefalopatias não progressivas, que se desenvolvem no cérebro, constituindo "um conjunto de quadros clínicos com variados sintomas patológicos mental e motor"1. O conhecimento existente acerca da SD e seu desenvolvimento têm proporcionado o entendimento de que o portador dessa síndrome pode levar uma vida normal bem como uma pessoa não portadora, podendo assim buscar uma melhor qualidade de vida, visto que as características visíveis causadas pela genética, não constituem obstáculos para isso ${ }^{4}$. Considerando isto, a prática de atividades físicas vem sendo uma alternativa para estimular os movimentos bem como o raciocínio, promovendo a capacidade de fortalecer e enriquecer o desenvolvimento físico, mental e social do indivíduo. Assim o presente trabalho trata-se de um relato de caso do jovem EN, portador da SD, sexo masculino e idade de 29 anos, que procurou acompanhamento de um educador físico no ano de 2008, aos 18 anos de idade, com o propósito de desenvolvimento muscular, emagrecimento e controle glicêmico. Inicialmente foi realizada uma abordagem nutricional, seguida de uma avaliação física. O exame físico seguiu o protocolo de coleta de dados antropométricos, peso, altura, índice de massa corpórea (IMC), encurtamento muscular, adiposidade, dobras cutâneas, composição corporal, e anamnese completa, segundo JACKSON \& POLLOCK, e análise pelo programa KINESIS Avaliação Física. Após a coleta deu-se início o proposto trabalho intensivo e progressivo, com enfoque no treino funcional, com base em exercícios proprioceptivos, de equilíbrio e lateralidade, além do reforço articular. Os treinos foram divididos em três vezes por semana, com duração de 50 minutos cada dia. O estudo foi realizado no período de 10/08/2008 ao período $12 / 08 / 2013$, onde foi analisado o processo hipertrófico, e o emagrecimento do jovem EN. Durante esse período verificou-se uma constância evolutiva no aumento da força muscular constatados pelos testes de uma repetição máxima (1RM), e uma redução do percentual de gordura. Assim, podem-se demonstrar vários benefícios ao indivíduo, tais como: melhora psicológica, cognitiva e da capacidade física individual, além do estímulo ao convívio social. O indivíduo que apresenta SD precisa de um acompanhamento ainda maior já que seu corpo apresenta maior flacidez, inclusive nas articulações ${ }^{5,3}$. Constatamos que a prática da musculação pode reverter várias complicações na vida do portador desta Síndrome e que o treino funcional é uma ótima maneira de tentar solucionar problemas como, redução da flacidez articular, aumento da densidade óssea, melhora cardiovascular, e melhora psicossocial e de interatividade. 


\section{REFERÊNCIAS BIBLIOGRÁFICAS}

${ }^{1}$ HOFMANN, A. P. Relação interpessoal de PNE (Síndrome de Down) na educação física na educação infantil (estudo de caso). Revista de Educação Física da Pontifícia Universidade Católica do Paraná, v. 3, n. 2, p. 638-643, 2010.

2JACKSON A. S.; POLLOCK M. L. Generalized equations for predicting body density of men. British Journal of Nutrition, v. 40, n. 3, p. 497-504, 1978.

${ }^{3}$ MODESTO, Everaldo Lambert; GREGUOL, Márcia. Efeito do exercício físico sobre a cinemática da marcha em pessoas com síndrome de down-uma revisão sistemática. Motrivivência, v. 31, n. 59, 2019.

${ }^{4}$ ORNELAS, M. A.; SOUZA, C. A contribuição do profissional de educação física na estimulação essencial em crianças com síndrome de Down. Revista da Educação Física/UEM, Maringá, v. 12, n. 1, p. 77-88, 2001.

${ }^{5}$ RIBEIRO, Monique Stephanie Piovan; NEVES, Thayná Souza; BALMANT, Bianca Depieri. Estado Nutricional, percentual de gordura e aspectos dietéticos de crianças e adolescentes com Síndrome de Down. In: Colloquium Vitae. ISSN: 1984-6436. 2019. p. 7-16. 


\section{USO DA SUPLEMENTAÇÃO DE CREATINA NA POPULAÇÃO IDOSA}

Rayssa Prado Rodrigues, Rafaela Candian Filgueiras Silva, Ingrid Morselli Santos, Priscila Cristian do Amaral, Daniela Carvalho Siqueira, Vinícius Azevedo Dias Contato: rayssaprador@gmail.com

Introdução: O envelhecimento está associado a redução da massa muscular, sendo a sarcopenia, uma condição que expõe a população idosa à risco aumentado para quedas, fraturas, incapacidade, dependência, hospitalização recorrente e mortalidade. Possivelmente, a suplementação de creatina tem sido utilizada, devido ao efeito ergogênico, com a finalidade de melhorar o desempenho físico e preservar a massa muscular evitando a sarcopenia nessa população. No entanto, as particularidades do indivíduo idoso como: idade, atividade física, peso, altura, comorbidades prévias, são relevantes na introdução da creatina, pois há recomendações diferentes para idosos saudáveis e para idosos com doenças crônicas ou agudas. Objetivo: Analisar os benefícios da suplementação de creatina em idosos. Metodologia: Foi feito uma pesquisa nas bases eletrônicas Pubmed e Scielo, no período de agosto de 2019, com publicações dos últimos 5 anos utilizando os seguintes descritores: creatina, idoso, sarcopenia e desempenho físico e seus correspondentes na língua inglesa. A busca retornou 11 artigos e para a presente revisão 4 foram selecionados. Resultados: Nos trabalhos avaliados, verificou-se efeitos benéficos da suplementação com creatina, incluindo redução da fadiga em atividades físicas; aumento da massa magra, força, potência muscular, desempenho, qualidade de vida; melhora da capacidade de remodelação óssea e retardamento da sarcopenia. Contudo, em idosos sedentários, a suplementação de creatina proporcionou modificações fisiológicas mínimas, corroborando com os estudos na população adulta que destacam o exercício como estimulante da captação dos nutrientes via celular, contribuindo para o catabolismo. Conclusão: A sarcopenia associada ao envelhecimento é um processo lento, progressivo e aparentemente inevitável, inclusive em indivíduos que praticam exercícios físicos regularmente. No entanto, o combate ao sedentarismo associado à suplementação de creatina nessa população foi benéfico por promover melhora no desempenho físico, aumento de força e manutenção da massa muscular em idosos.

Referências bibliográficas

1. Zdzieblik et al. Collagen peptide supplementation in combination with resistance training improves body composition and increases muscle strength in elderly sarcopenic men: a randomised controlled trial Br J Nutr. 2015 Oct 28; 114(8): 1237-1245. doi: $10.1017 / \mathrm{S} 0007114515002810$

2. Peruchi et al. Nutritional supplements in the elderly (amino acids, proteins, pufas, vitamn $D$ and zinc) with emphasis on sarcopenia: a systematic review. Uningá Review. Jun/2017; V.30, n.2, pp.61-69.

Divinópolis/MG

2019
3. Pícoli Tatiane da Silva, Figueiredo Larissa Lomeu, Patrizzi Lislei Jorge. Sarcopenia and aging. Fisioterapia e movimento [Internet]. 2017 set. 11 [citado em 2019 ago. 9]; disponível em: http://www.scielo.br/pdf/fm/v24n3/10.pdf.

4. Alves CRR, et al. Efeito da suplementação de creatina, associada ou não ao treinamento de força, sobre a peroxidação lipídica em mulheres idosas. Rev Bras Educ Fís Esporte, (São Paulo) 2014 Jan-Mar; 28(1):13-21. Disponível em: [citado em 2019 ago. 10]; Disponível em: http://www.scielo.br/pdf/fm/v24n3/10.pdf. 